\title{
Full-Length $\mathrm{Ga}_{\mathrm{q}}-$ Phospholipase C- $\beta 3$ Structure Reveals Interfaces of the C-terminal Coiled-Coil Domain
}

\author{
Angeline M. Lyon ${ }^{1,2,3}$, Somnath Dutta ${ }^{1,3, \dagger}$, Cassandra A. Boguth ${ }^{1, \dagger}$, Georgios Skiniotis $^{1,3}$, \\ and John J. G. Tesmer ${ }^{1,2,3}$ \\ ${ }^{1}$ Life Sciences Institute, University of Michigan, Ann Arbor, MI, United States. \\ ${ }^{2}$ Department of Pharmacology, University of Michigan, Ann Arbor, MI, United States. \\ ${ }^{3}$ Department of Biological Chemistry, University of Michigan, Ann Arbor, MI, United States.
}

\section{Abstract}

Phospholipase C- $\beta$ (PLC $\beta$ ) is directly activated by $\mathrm{Ga}_{\mathrm{q}}$, but the molecular basis for how its distal C-terminal domain (CTD) contributes to maximal activity is poorly understood. Herein we present both the crystal structure and cryo-EM 3D reconstructions of human full-length PLC $\beta 3$ in complex with murine $\mathrm{Ga}_{\mathrm{q}}$. The distal CTD forms an extended, monomeric helical bundle consisting of three anti-parallel segments with structural similarity to membrane-binding bin-amphiphysin-Rvs (BAR) domains. Sequence conservation of the distal CTD identifies putative membrane and protein interaction sites, the latter of which bind the $\mathrm{N}$-terminal helix of $\mathrm{Ga}_{\mathrm{q}}$ in both the crystal structure and cryo-EM reconstructions. Functional analysis suggests the distal CTD plays roles in membrane targeting and in optimizing the orientation of the catalytic core at the membrane for maximal rates of lipid hydrolysis.

\begin{abstract}
Phospholipase C (PLC) isozymes hydrolyze the inner membrane lipid phosphatidylinositol-4,5-bisphosphate $\left(\mathrm{PIP}_{2}\right)$ to generate the second messengers diacylglycerol and inositol 1,4,5-triphosphate $\left(\mathrm{IP}_{3}\right)$, which in turn promote the release of intracellular calcium and activate protein kinase $\mathrm{C}(\mathrm{PKC})^{1,2}$. Among the PLC subfamilies, PLC $\beta$ enzymes are unique in their ability to be stimulated via direct interactions with the heterotrimeric $\mathrm{G}$ protein subunits $\mathrm{Ga}_{\mathrm{q}}$ and $\mathrm{G} \beta \gamma^{3-5}$. PLC $\beta$ proteins contribute to diverse cellular functions, including chemotaxis ${ }^{6}$, neural signaling ${ }^{7}$ and opioid sensitivity ${ }^{8}$. More recently, excess $\mathrm{Ga}_{\mathrm{q}}$ signaling has been implicated in the development of ocular cancer ${ }^{9}$. One of the best characterized roles of PLC $\beta$ is in the cardiovascular system, where it
\end{abstract}

\footnotetext{
Users may view, print, copy, download and text and data- mine the content in such documents, for the purposes of academic research, subject always to the full Conditions of use: http://www.nature.com/authors/editorial_policies/license.html\#terms

Correspondence should be addressed to: John J. G. Tesmer (johntesmer@umich.edu), Telephone: (734) 615-9544, Fax: (734)

763-6492.

Authors contributed equally to this work.

ACCESSION CODES

Coordinates and diffraction intensities for the $\mathrm{Ga}_{\mathrm{q}}-\mathrm{PLC} \beta 3$ complex are deposited with the Protein Data Bank as entry 4GNK.

AUTHOR CONTRIBUTIONS

A.M.L., G.S., and J.J.G.T. designed the overall experimental approach. A.M.L. and C.A.B. cloned, expressed and purified all $\mathrm{Ga}_{\mathrm{q}}$ and PLC 33 variants and conducted FCPIA assays. A.M.L. carried out all activity-based assays. A.M.L. and C.A.B. crystallized the $\mathrm{Ga}_{\mathrm{q}}-$ PLC $\beta 3$ complex, and A.M.L. determined the structure. S.D. and G.S. carried out all cryo-EM experiments. A.M.L., S.D., G.S., and J.J.G.T. co-wrote the manuscript.
} 
regulates cardiomyocyte and vascular smooth muscle function ${ }^{10-12}$. Maladaptive changes in these pathways can result in the onset and maintenance of cardiac arrhythmias ${ }^{13}$, cardiac hypertrophy ${ }^{14,15}$, and heart failure ${ }^{16,17}$.

Like most other PLC enzymes, PLC $\beta$ contains an N-terminal pleckstrin homology (PH) domain, four tandem EF hand repeats, a triose phosphate isomerase (TIM) barrel-like catalytic domain separated into $\mathrm{X}$ and $\mathrm{Y}$ halves by the $\mathrm{X}-\mathrm{Y}$ linker, and a $\mathrm{C} 2$ domain ${ }^{1,2}$, which forms the catalytic core of the enzyme. Unlike other PLC isoforms, PLC $\beta$ also has a $\sim 400$ amino acid C-terminal extension to the catalytic core that contains the proximal and distal C-terminal domains (CTDs) ${ }^{18,19}$ separated by a non-conserved, low complexity linker of variable length (Fig. 1a, Supplementary Fig. 1). The proximal CTD is a highly conserved $\sim 40$ amino acid segment that contains the principal binding site for activated $\mathrm{Ga}_{\mathrm{q}}$ (the $\mathrm{Ha1}$ Ha2 hairpin $)^{18}$ followed by an autoinhibitory helix (Ha2') that binds to the catalytic core ${ }^{19}$. When $\mathrm{Ga}_{\mathrm{q}}$ binds to the hairpin, the Ha2' helix is displaced from the catalytic core, leading to enhanced lipid hydrolysis. The distal CTD is less well conserved but numerous studies suggest that it is important for full activity, membrane binding, regulation by $\mathrm{Ga}_{\mathrm{q}}$, and GAP activity ${ }^{19-29}$. However, the molecular basis for how it contributes to these processes remains poorly defined even in light of the structure of a distal CTD from turkey PLC $\beta{ }^{26}$. To elucidate a structural basis for the functional roles of the distal CTD, we used X-ray crystallography and single particle electron cryo-microscopy (cryo EM) to determine the structure of human full-length PLC $\beta 3$ in complex with activated $\mathrm{Ga}_{\mathrm{q}}$, revealing the distal $\mathrm{CTD}$ in the context of a fully functional signaling complex where it forms unanticipated interactions with $\mathrm{Ga}_{\mathrm{q}}$ and the catalytic core of PLC $\beta$ that likely contribute to regulation.

\section{RESULTS}

\section{Crystal Structure of $\mathrm{Ga}_{\mathrm{q}}$ in Complex with Human PLC $\beta 3$}

The $\mathrm{Ga}_{\mathrm{q}}-\mathrm{PLC} \beta 3$ complex crystallized as an asymmetric dimer, with the two-fold interface mediated by the Rac1-binding surface of the PH domains (Table 1, Fig. 1b, Supplementary Fig. 2a). Each $\mathrm{Ga}_{\mathrm{q}}-\mathrm{PLC} \beta 3$ catalytic core complex is similar to the structure of $\mathrm{Ga}_{\mathrm{q}}$ in complex with PLC $\beta 3-\triangle 887$ (PDB entry $3 \mathrm{OHM}^{18}$ ) (r.m.s.d. of $0.57 \AA$ for $932 \mathrm{Ca}$ atoms from $\mathrm{Ga}_{\mathrm{q}}$ and residues 11-867 of PLC $\beta 3$ ), although the relative orientation of $\mathrm{Ga}_{\mathrm{q}}$ with respect to the catalytic core differs from $3 \mathrm{OHM}$ by $3^{\circ}$ in each $\mathrm{Ga}_{\mathrm{q}}-\mathrm{PLC} \beta 3$ catalytic core complex. The greatest conformational differences are observed in the $\beta 1-\beta 2$ and $\beta 5-\beta 6$ loops of the $\mathrm{PH}$ domain, likely due to their contribution to the dimer interface (Supplementary Fig. 2b), and in the Ha2' helix, which adopts a different orientation in each of the $\mathrm{Ga}_{\mathrm{q}}-\mathrm{PLC} \beta 3$ complexes in this structure and the 3OHM structure (Supplementary Fig. 2c).

Only one copy of the distal CTD is observed in the asymmetric unit, despite the preponderance of full length PLC $\beta 3$ in the crystals (Supplementary Fig. 3), suggesting the other distal CTD is disordered rather than proteolyzed. The CTD linker (residues 883-933) is not observed in the structure, and thus the distal CTD could be attached to a number of different adjacent catalytic cores in the crystal lattice (e.g. Supplementary Fig. 4). The distal CTD (residues 934-1192) consists of three primarily anti-parallel helical segments that extend nearly the full-length $(\sim 140 \AA$ ) of the domain (Fig. 1b, 2a). The first segment contains the Da1 (residues 935-946), Da2 (954-958) and Da3 (960-1008) helices. Da3 
forms an extended anti-parallel coiled-coil interaction with the Da4 helix (residues 10271107) in the second segment. Da4 in turn forms an extended anti-parallel coiled-coil interaction with Da5 (residues 1115-1183) in the third segment. The Da1 and Da2 helices at the beginning of the first segment, and Da6 (residues 1184-1192) at the end of the third segment, form "arms" that cross the same face of the domain and pack against the principal helices of the other two segments (Fig. 1b, 2a).

Although clearly sharing the same fold, the PLC $\beta 3$ distal CTD superimposes poorly with that of turkey PLC $\beta$ (PDB entry $1 \mathrm{JAD}^{26}$ ) (Fig. 2a), with an r.m.s.d. of $4.4 \AA$ for the Da2Da6 helices (197 Ca atoms), much higher than the expected $1.6 \AA$ r.m.s.d. based on sequence identity alone $(27 \%)^{30}$. One difference lies in the Da5 helix, which is kinked in the PLC $\beta 3$ CTD structure by Pro1166. A second difference is that the PLC $\beta 3$ CTD is more curved than the turkey CTD, such that when the two domains are superimposed, the ends of the PLC $\beta 3$ domain are bent more towards the side of the domain with the "arms". This could be due to differences in the crystal packing of each structure, or to the fact that the turkey CTD crystallized as a homodimer, or to the multiple protein-protein interactions formed by the PLC $\beta 3$ distal CTD within its crystal lattice, or to a combination of all these factors. Although the turkey CTD contained a deletion in the Da3-Da4 loop at one end of the domain, this deletion corresponds to residues that are disordered in the PLC $\beta 3$ CTD and are therefore unlikely to be responsible for global differences in domain conformation. A homology search using Dali ${ }^{31}$ confirmed the structural similarities between the distal CTD and the turkey CTD structure (Z-scores of 15.4 and 8.6 for the B and A chains of the turkey CTD homodimer, respectively) as well as homology to bin-amphiphysin-Rvs (BAR) domains, with Z-scores between 6.7-8.3. BAR domains are also extended helical bundles composed of three helical segments and have a similar topology (Supplementary Fig. 5). BAR domains interact nonspecifically with negatively charged phospholipids, as has been reported for the PLC $\beta$ isozymes ${ }^{25,28,29,32}$, and can sense and/or induce membrane curvature $^{33,34}$.

\section{Conservation of the Distal CTD Reveals Putative Interaction Surfaces}

Most of the highly conserved residues in the distal CTD (Supplementary Fig. 1) are hydrophobic and pack between the three segments of the domain to form a hydrophobic core, with the largest cluster located at the interface of the Da2, Da4, and Da5 helices at the center of the domain (Fig. 2b). Two other clusters of conserved residues are on the surface of the domain and likely serve other functions. A ridge of highly conserved basic residues runs along the same face of the Da3 and Da4 helices (Fig. 2c) and constitutes a potential membrane-interaction site. Indeed, previous studies found that deletion of the distal CTD abolishes particulate association ${ }^{21,23,25,28}$, and mutation of conserved basic residues within Da3 of PLC $\beta 1$ impairs maximal $\mathrm{Ga}_{\mathrm{q}}$-stimulated activity ${ }^{21,27}$. The electrostatic surface of the domain (Fig. 2d) is also consistent with the ability to bind negatively charged membranes. Some BAR domains also have basic patches located at similar topological positions to those observed in Da3 and Da4, suggesting a functional relationship with the PLC $\beta$ distal CTD $^{33-35}$. A second patch of conserved surface residues is formed by residues Ile1129, Val1133, and Ile1136 in the Da5 helix (Fig. 2c). This region is orthogonal to the 
putative membrane-binding surface, and may therefore represent a protein-protein interaction site involved in regulation of PLC $\beta$ at the membrane.

\section{Solution Architecture of the $\mathrm{Ga}_{\mathrm{q}}-\mathrm{PLC} \beta 3$ Complex}

The distal CTD makes several direct contacts with $\mathrm{Ga}_{\mathrm{q}}$ and the catalytic core of PLC $\beta 3$ in the crystal lattice. Although of all these interactions could not be formed at the same time by a single distal CTD in the context of a PLC $\beta$ monomer, each one represents an interaction that could contribute to activity and/or regulation. To identify which of the interactions made by the distal CTD also occur in solution, we used single particle cryo-EM to determine the solution structure of the $\mathrm{Ga}_{\mathrm{q}}-\mathrm{PLC} \beta 3$ complex. A combination of thin vitrified ice and CCD image acquisition under an electron accelerating voltage of $120 \mathrm{kV}$ allowed adequate contrast for alignment of the $\sim 180 \mathrm{kDa}$ protein particle projections (Fig. 3). We initially calculated a preliminary $3 \mathrm{D}$ reconstruction from our entire dataset of 40,124 projections by using the $\mathrm{Ga}_{\mathrm{q}}-\mathrm{PLC} \beta 3$ structure without the distal CTD as initial reference. The reconstruction was characterized by relatively poor definition for the $\mathrm{Ga}_{\mathrm{q}}-\mathrm{PLC} \beta 3$ core, and lacked clear density for the distal CTD. Instead, several noise-like densities appeared at various positions about the core complex (Supplementary Fig. 6).

To test whether the observed peripheral densities corresponded to flexibility or multiple distinct conformations of the distal CTD with respect to the catalytic core, we employed multiple 3D reference-supervised classification to categorize the cryo-EM projections. The categorization was based on the similarities of projections to reprojections of four $20 \AA$ filtered volumes representing different direct $\mathrm{Ga}_{\mathrm{q}}-\mathrm{PLC} \beta 3$ interactions with the distal CTD that were observed in the crystal lattice. We then used the cryo-EM projections in each category to generate four independent $3 \mathrm{D}$ reconstructions, all using the same starting reference, which corresponded to a $20 \AA$-filtered volume of the $\mathrm{Ga}_{\mathrm{q}}-\mathrm{PLC} \beta 3$ catalytic core without the distal CTD (Fig. 3). The omission of the CTD density in the reference volume ensured that we eliminated any reference bias for its position with respect to the catalytic core.

The majority of cryo-EM projections showed good agreement with two of the initial reference structures ( $>30 \%$ of projections each, Fig. 3). These two subgroups provided 3D reconstructions with very good definition for the core complex and additional elongated density attached at two different positions (Fig. 4a, b). These non-biased reconstructions (for the CTD), with estimated resolutions of $19 \AA$ and $21 \AA$ (at FSC=0.5, Supplementary Fig. 7), showed excellent agreement with the two corresponding models used for particle categorization with a cross-correlation greater than 0.93 . In contrast, the other subgroups (with $\sim 18 \%$ of projections each, Fig. 3) not only failed to reveal a clear density for the distal $\mathrm{CTD}$, but also showed very poor volumes for the $\mathrm{Ga}_{\mathrm{q}}-\mathrm{PLC} \beta 3$ core complex. This may indicate that the orientation of the distal CTD within these subgroups is highly variable, resulting in overall projection misalignment and consequently poor quality $3 \mathrm{D}$ reconstructions.

Therefore, under our experimental conditions, two of the interactions of the distal CTD are favored in solution and recapitulated in the crystal lattice (Fig. 4). Both involve conserved residues. The first interaction is between the distal CTD and the N-terminal amphipathic 
helix of $\mathrm{Ga}_{\mathrm{q}}$ (Fig. 4a, c). The second is between the distal CTD and the hydrophobic ridge of the PLC $\beta 3$ catalytic core (Fig. 4b, d), a cluster of conserved and solvent exposed hydrophobic residues adjacent to the active site that are thought to insert into the membrane and promote catalysis ${ }^{36,37}$. The latter interaction would therefore be predicted to simultaneously hinder access of substrates into the active site and prevent the conserved basic patch on Da3 from interacting with membranes.

\section{Functional Analysis of the $\mathrm{Ga}_{\mathrm{q}} \mathrm{N}$-terminus-Distal CTD Interaction}

To assess the significance of the interaction between the distal CTD and the N-terminal helix of $\mathrm{Ga}_{\mathrm{q}}$ (Fig. 4a, c) we expressed a truncated $\mathrm{Ga}_{\mathrm{q}}$ in which the first 36 residues, corresponding to its N-terminal helix, were deleted $\left(\mathrm{Ga}_{\mathrm{q}}-\Delta \mathrm{N}\right)$, and a PLC $\beta 3$ I1129E V1133E I1136E triple mutant (PLC $\beta 3$ EEE), which eliminates the hydrophobic patch on Da5. We used a liposome-based assay to measure the rates of basal and $\mathrm{Ga}_{\mathrm{q}}$-stimulated $\mathrm{PIP}_{2}$ hydrolysis. The maximum activities of PLC $\beta 3$ and PLC $\beta 3$ L876A, which contains a mutation that abrogates $\mathrm{Ha} 2$ ' autoinhibition, were significantly lower when stimulated by $\mathrm{Ga}_{\mathrm{q}}-\Delta \mathrm{N}$ than wild-type $\mathrm{Ga}_{\mathrm{q}}$ (Table 2, Supplementary Fig. 8a, b). The $\mathrm{Ga}_{\mathrm{q}}$-stimulated activities of PLC $\beta 3$ EEE and PLC $\beta 3$ L876A EEE were also significantly reduced compared to wild-type PLC $\beta 3$ and PLC $\beta 3$ L876A, respectively. Conversely, the activities of PLC $\beta 3$ $\Delta 892$, which lacks the distal CTD, and PLC $\beta 3$ EEE were the same for $\mathrm{Ga}_{\mathrm{q}}$ and $\mathrm{Ga}_{\mathrm{q}^{-}}-\Delta \mathrm{N}$, indicating these PLC $\beta 3$ variants were insensitive to the presence of the $\mathrm{N}$-terminal helix of $\mathrm{Ga}_{\mathrm{q}}$ (Table 2).

We also tested whether perturbation of the $\mathrm{Ga}_{\mathrm{q}}$ interfaces formed by the distal CTD would decrease binding affinity for activated $\mathrm{Ga}_{\mathrm{q}}$. We used a flow cytometry-based bead-binding assay to measure the ability of PLC $\beta 3$ variants to displace a fluorescently labeled mutant of PLC 33 (PLC $\beta 3-\triangle 892$ R872A L876A L879A) ${ }^{19}$ from bead-bound $\mathrm{Ga}_{\mathrm{q}}$. In this assay, PLC $\beta 3$ bound $\mathrm{Ga}_{\mathrm{q}}$ with higher affinity than PLC $\beta 3-\Delta 892\left(K_{\mathrm{i}}\right.$ values of $220 \pm 30 \mathrm{nM}$ and $490 \pm 66$ $\mathrm{nM}$, respectively), but with significantly less affinity than PLC $\beta 3$ L876A $\left(K_{\mathrm{i}}=20 \pm 3.2 \mathrm{nM}\right)$ (Table 2, Supplementary Fig. 8c), consistent with the L876A mutation abrogating the autoinhibitory interaction of $\mathrm{Ha} 2^{\prime}$ with the catalytic core ${ }^{19}$. Although these $K_{\mathrm{i}}$ values are overall higher than reported in prior studies ${ }^{19}$, they maintain the same trends. The values are also higher than the $\mathrm{EC}_{50}$ values we measured for activation. This is likely because the beadbinding assay lacks liposomes, which likely enhance the apparent affinity of $\mathrm{Ga}_{\mathrm{q}}$ and PLC $\beta 3$. We next tested whether the interaction between the distal CTD and the N-terminal helix of $\mathrm{Ga}_{\mathrm{q}}$ was responsible for the difference in binding affinities between PLC $\beta 3$ and PLC $\beta 3-\Delta 892$, using the $\mathrm{Ga}_{\mathrm{q}}-\Delta \mathrm{N}$ and PLC $\beta 3$ EEE variants to abolish the interface. However, neither variant showed a significant binding defect (Table 2, Supplementary Fig. 8d), consistent with their similar $\mathrm{EC}_{50}$ values for activation. Thus, our results support the conclusion that a direct interaction between the $\mathrm{N}$-terminus of $\mathrm{Ga}_{\mathrm{q}}$ and the hydrophobic patch of Da5 in the distal CTD occurs during catalysis that is required for full efficacy, but not potency.

\section{$\mathrm{Ga}_{\mathrm{q}}$ Palmitoylation Also Contributes to Full Efficacy}

$\mathrm{The}_{\mathrm{Ga}}$ proteins used in these experiments were purified from the soluble fraction of baculovirus-infected insect cells, but some fraction of these proteins may retain palmitoyl 
groups at Cys9 and Cys10 (ref. ${ }^{38}$ ), which could account for the higher efficacy observed for full-length $\mathrm{Ga}_{\mathrm{q}}$ relative to $\mathrm{Ga}_{\mathrm{q}}-\Delta \mathrm{N}$. Acyl-biotin exchange chemistry confirmed at least a fraction of the purified $\mathrm{Ga}_{\mathrm{q}}$ was palmitoylated (Supplementary Fig. 9). Thus, we assessed the ability of palmitoylation-defective $\mathrm{Ga}_{\mathrm{q}}\left(\mathrm{Ga}_{\mathrm{q}} \mathrm{C} 9 \mathrm{~S} \mathrm{C} 10 \mathrm{~S}\right)$ to activate PLC $\beta 3$ variants (Table 2, Supplementary Fig. 8b). $\mathrm{Ga}_{\mathrm{q}}-\Delta \mathrm{N}$ and $\mathrm{Ga}_{\mathrm{q}}$ C9S C10S activated PLC $\beta 3$ and PLC $\beta 3$ L876A with similarly low efficacies, indicating that palmitoylation does contribute to the higher efficacy observed for wild-type $\mathrm{Ga}_{\mathrm{q}}$ in vitro. However, palmitoylated $\mathrm{Ga}_{\mathrm{q}}$ likely increases PLC $\beta 3$ activity through a mechanism other than increased localization of the complex to vesicles, as it does not seem to increase association of PLC $\beta 3$ with membranes ${ }^{25,38,39}$. PLC $\beta 3-\Delta 892$ was activated to similar extents by $\mathrm{Ga}_{\mathrm{q}}, \mathrm{Ga}_{\mathrm{q}}-\Delta \mathrm{N}$ and $\mathrm{Ga}_{\mathrm{q}}$ C9S C10S (Table 2), indicating that the palmitoylation status of $\mathrm{Ga}_{\mathrm{q}}$ is irrelevant in the absence of the distal CTD.

\section{PLC $\beta 3$ and the $\mathrm{Ga}_{\mathrm{q}}-\mathrm{PLC} \beta 3$ Complex Are Monomeric}

The residues that comprise the hydrophobic patch in Da5 contribute to a homodimer interface in the turkey distal CTD structure ${ }^{26}$. Therefore, defects in specific activity exhibited by mutants such as PLC $\beta 3$ EEE could be attributed to disruption of the dimer interface. In addition, dimerization of the distal CTD, though structurally incompatible with the $\mathrm{Ga}_{\mathrm{q}} \mathrm{N}$-terminal helix-distal CTD interaction (Fig. 4a, c), could occur simultaneously with the PLC $\beta 3$ core-distal CTD interface (Fig. 4b, d). We therefore tested whether fulllength PLC $\beta 3$ or $\mathrm{Ga}_{\mathrm{q}}-\mathrm{PLC} \beta 3$ formed higher order complexes using multi-angle light scattering. PLC $\beta 3$ and $\mathrm{Ga}_{\mathrm{q}}-\mathrm{PLC} \beta 3$ elute from a WTC-050S5 silica-based column with molecular weights of $152 \mathrm{kDa}$ and $182 \mathrm{kDa}$, respectively, very close to the expected molecular weights for monomeric PLC $\beta 3$ (139 kDa) and $\mathrm{Ga}_{\mathrm{q}}-\mathrm{PLC} \beta 3$ species (181 kDa). Furthermore, cryo-EM images of the $\mathrm{Ga}_{\mathrm{q}}-\mathrm{PLC} \beta 3$ complex incubated on the surface of $\mathrm{PIP}_{2}$ lipid monolayers did not reveal higher order assemblies of the complex (data not shown), suggesting membrane association does not induce oligomerization. Thus, the differences in efficacy measured for mutants such as PLC $\beta 3$ EEE do not seem to be linked to changes in the oligomeric state of the enzyme.

\section{Analysis of Other Interfaces of the Distal CTD Formed in Crystals}

The interface formed between the distal CTD and the PLC $\beta 3$ hydrophobic ridge (Fig. 4b, d) could represent a mechanism by which the distal CTD contributes to the regulation of basal activity. We therefore generated Leu341, Phe381, Met383, Thr652, and Val654 point mutants in both PLC $\beta 3$ and PLC $\beta 3$ - $\triangle 892$. Of these, only T652E could be expressed and purified in the background of the PLC $\beta 3$ construct, suggesting these residues are essential for protein folding and/or stability. PLC $\beta 3$ T652E and PLC $\beta 3-\triangle 892$ T652E showed significant decreases in basal activity, higher $\mathrm{EC}_{50}$ values, and greatly reduced efficacies upon $\mathrm{Ga}_{\mathrm{q}}$ activation, confirming the importance of the hydrophobic ridge in PLC $\beta 3$ for overall activity (Table 2). The activity of the T652E mutant was the same regardless of the presence of the distal CTD, suggesting that the distal CTD does not influence basal activity. However, our inability to confirm this with other mutations in this region renders interpretation difficult. 
The distal CTD also contacts the Ras-like domain of $\mathrm{Ga}_{\mathrm{q}}$, burying $\sim 850 \AA^{2}$ of surface area (Supplementary Fig. 2d). In this interaction, the $\mathrm{Ga}_{\mathrm{q}} \mathrm{a} 3-\mathrm{a} 4$ loop and $\mathrm{a} 4$ helix interact with residues in Da3 and Da4 of the distal CTD. Ga $\mathrm{q}_{\mathrm{q}}$ Pro298 forms a hydrophobic contact with the side chains of $\operatorname{Arg} 1062$ and Gln1066 in $\mathrm{aB}$, and electrostatic interactions are formed between $\mathrm{Ga}_{\mathrm{q}}$ Asp296 and K311A and Da3 residues Arg969, Asp973, and Glu976. To test this interaction, we expressed D296A P298D and K311A variants of $\mathrm{Ga}_{\mathrm{q}}$ and tested their ability to bind and activate PLC $\beta 3$ variants. All were able to activate PLC $\beta 3$ variants with $\mathrm{EC}_{50}$ values and maximum activity comparable to wild-type $\mathrm{Ga}_{\mathrm{q}}$, although $\mathrm{EC}_{50}$ values for D296A P298D were elevated. However, none had a significant effect on binding affinity (Table 2).

Another interaction observed in crystals is between the Da3-Da4 loop of the distal CTD and the second $\mathrm{EF}$ hand (Ea2 and Fa2 helices) of the catalytic core. Although this interaction is sufficient to cause a conformational change in a loop of the EF hand relative to the $3 \mathrm{OHM}$ structure and the other chain of PLC $\beta 3$ in our structure, the residues involved in this interaction are poorly conserved and not well ordered. Indeed, Da3-Da4 loop residues 1009-1026 could not be modeled. Thus, this interaction most likely represents a simple crystal contact.

\section{The CTD Linker Is Required for $\mathrm{Ga}_{\mathrm{q}}$ Activation}

Point mutants of residues in the hydrophobic ridge that interact with the distal CTD suggest that these positions are essential for folding and basal activity, consistent with their proposed role in catalysis. We therefore indirectly tested this interface by deleting the CTD linker, which should prevent the distal CTD from forming any of the interactions observed in the crystal lattice or by cryo-EM. PLC $\beta 3-\Delta 882-938$ showed a significant increase in basal activity compared to PLC $\beta 3$ (Table 2). This increase could be attributed to a loss of autoinhibition mediated by the distal CTD or to an increase in the local concentration of the catalytic core at the membrane by virtue of a shorter linker. However, deletion of the CTD linker had no significant effect on basal activity in the background of PLCB3 L876A (Table 2). Thus the mechanism by which basal activity is increased is not clear. Strikingly, $\mathrm{Ga}_{\mathrm{q}}$ failed to activate PLC $\beta 3-\Delta 882-938$ or PLC $\beta 3-\Delta 882-938$ L876A at all concentrations tested (Table 2, Supplemental Fig. 8a) even though both proteins bound $\mathrm{Ga}_{\mathrm{q}}$ with comparable affinity to PLC $\beta 3$ and PLC $\beta 3$ L876A, respectively (Table 2, Supplementary Fig. 8c). Because the sequence of the CTD linker is not conserved among PLC $\beta$ isozymes, its length and/or flexibility seems to be required for the proximal and distal CTDs to make all the interactions necessary for activation by $\mathrm{Ga}_{\mathrm{q}}$.

\section{DISCUSSION}

The structure of $\mathrm{Ga}_{\mathrm{q}}$ in complex with full-length human PLC $\beta 3$ provides new insights into the structure and potential functions of the enigmatic distal CTD of PLC $\beta$ isozymes. One edge of this domain bears highly conserved basic residues that likely directly interact with negatively charged membranes. Structural similarity between the distal CTD and BAR domains (Supplementary Fig. 5) is also consistent with membrane targeting being a key role for the distal CTD, and raises the possibility that the distal CTD may likewise sense or 
influence membrane curvature ${ }^{33,34}$. Orthogonal to this surface is a conserved hydrophobic patch that interacts with the amphipathic $\mathrm{N}$-terminal helix of $\mathrm{Ga}_{\mathrm{q}}$ in both the crystal structure and cryo-EM reconstructions. Our in vitro functional analysis supports a role for this interaction in promoting full efficacy of activation by $\mathrm{Ga}_{\mathrm{q}}$. However, oligomerization does not appear to play a role in this process ${ }^{26}$ as PLC $\beta 3$ and the $\mathrm{Ga}_{\mathrm{q}}-\mathrm{PLC} \beta 3$ complex are monomeric by structural analysis and multi-angle light scattering.

Our structural and functional analysis of the distal CTD in the context of a fully functional signaling complex allows re-interpretation of prior functional studies. Ilkeava et a ${ }^{27}$ identified five regions in the distal CTD of rat PLC $\beta 1$ that caused significant defects in $\mathrm{Ga}_{\mathrm{q}}$ activation and GAP activity ("Group III" mutants; Supplementary Fig. 1). The first three regions perturbed the conserved basic residues in Da3 and Da4 that we propose to be involved in membrane binding. The fourth region perturbed the hydrophobic patch that interacts with the $\mathrm{N}$-terminus of $\mathrm{Ga}_{\mathrm{q}}$. Site-directed mutation of the conserved basic residues (particularly within Da3) reduced $\mathrm{Ga}_{\mathrm{q}}$-stimulated activity and greatly reduced association with the particulate fraction of cells ${ }^{21}$. Considered along with our data, substitution of the conserved basic residues most likely decreases $\mathrm{Ga}_{\mathrm{q}}$-stimulated activity because the enzyme is impaired in its ability to associate with the membrane where its substrate is located.

Defects in GAP activity resulting from perturbations of the distal CTD could likewise be explained as defects in membrane binding, as this property was measured in steady state assays using receptor and heterotrimeric $\mathrm{G}$ proteins reconstituted in lipid vesicles ${ }^{27}$.

However, membrane binding is clearly not the sole function of the distal CTD. Perturbation of the hydrophobic patch in Da5 leads to a significant decrease in maximum $\mathrm{Ga}_{\mathrm{q}}$-stimulated activity, despite the presence of palmitoylated $\mathrm{Ga}_{\mathrm{q}}$ and an intact membrane-binding surface on the distal CTD. Furthermore, deletion of the CTD linker leads to complete loss of $\mathrm{Ga}_{\mathrm{q}}$ activation in our assays (Table 2, Supplementary Fig. 8a). The simplest explanation for these observations is that the interaction between the distal CTD and the palmitoylated N-terminus of $\mathrm{Ga}_{\mathrm{q}}$ optimizes the orientation of the catalytic core at the membrane (Fig. 5) ${ }^{1}$. Thus, activation of the enzyme by $\mathrm{Ga}_{\mathrm{q}}$ is at least a combination of allosteric control (e.g. release of autoinhibition by $\left.\mathrm{Ha}^{2}\right)^{19}$ and proper positioning of the catalytic core. Either or both of these processes could also influence displacement of the $\mathrm{X}-\mathrm{Y}$ linker from the active site through a process of interfacial activation ${ }^{18,40}$.

Adding to the complexity is the regulation of PLC $\beta$ by G $\beta \gamma$ subunits ${ }^{4,41}$ and small GTPases ${ }^{42,43}$. G $\beta \gamma$ and small GTPases are typically geranylgeranylated, resulting in their constitutive association with the cell membrane. Activation by G $\beta \gamma$ and Rac1 has also been proposed to involve the optimization of the orientation of the PLC $\beta$ active site at the membrane ${ }^{43,44}$, but the role of the distal CTD in response to these activators is less clear. Future structural studies will be essential in understanding how G $\beta \gamma$ interacts with and activates PLC $\beta$, in some cases synergistically with $\mathrm{Ga}_{\mathrm{q}}{ }^{45,46}$. 


\section{ONLINE METHODS}

\section{Protein expression, purification, and mutagenesis}

N-terminally His-tagged human PLC $\beta 3$ (residues 10-1234) and variants were expressed in baculovirus infected insect cells and purified as described previously ${ }^{19}$, with the modification that resuspended cells were lysed by douncing on ice. Murine $\mathrm{Ga}_{\mathrm{q}}$ (residues 7359) and variants were expressed and purified with a TEV-cleavable N-terminal His-tag as described previously ${ }^{19}$, with some modifications. Following elution from an Ni-NTA column, the protein was concentrated and applied to two tandem Superdex S200 columns

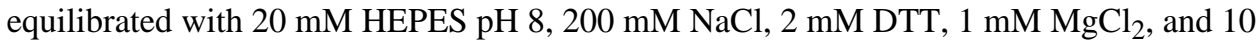
$\mu \mathrm{M}$ GDP. $\mathrm{Ga}_{\mathrm{q}}$ used for complex crystallization had the His-tag removed by the addition of TEV protease at $2 \%(\mathrm{w} / \mathrm{w})$ of $\mathrm{Ga}_{\mathrm{q}}$, then dialyzed overnight at $4{ }^{\circ} \mathrm{C}$ in Buffer $\mathrm{B}(20 \mathrm{mM}$ HEPES pH 8, $100 \mathrm{mM} \mathrm{NaCl}, 10 \mathrm{mM} \beta \mathrm{ME}, 3 \mathrm{mM} \mathrm{MgCl}$, and $10 \mu \mathrm{M}$ GDP). Following dialysis, the proteins were applied to a Ni-NTA column pre-equilibrated with Buffer $\mathrm{B}$. The flow-through, containing TEV-cleaved $\mathrm{Ga}_{\mathrm{q}}$, was collected, passed through the column three times, then concentrated and applied to two tandem Superdex S200 columns. Point mutations and internal deletions in the coding regions of PLC $\beta 3$ and $\mathrm{Ga}_{\mathrm{q}}$ were introduced using QuikChange Site-Directed Mutagenesis (Stratagene), and were confirmed by sequencing over the entire open reading frame.

\section{Purification of the $\mathrm{Ga}_{\mathrm{q}}-\mathrm{PLC} \beta 3$ Complex}

TEV-cleaved $\mathrm{Ga}_{\mathrm{q}}$ was incubated on ice with Buffer C (20 mM HEPES pH 8, $200 \mathrm{mM}$ $\mathrm{NaCl}, 2 \mathrm{mM}$ DTT, $0.9 \mathrm{mM} \mathrm{CaCl}_{2}, 5 \mathrm{mM} \mathrm{MgCl}_{2}, 10 \mathrm{mM} \mathrm{NaF}, 30 \mu \mathrm{M} \mathrm{AlCl}_{3}$, and $50 \mu \mathrm{M}$ GDP) for 15-20 min. Purified PLC $\beta 3$ was added to $\mathrm{Ga}_{\mathrm{q}}$ in a 1:1.2 molar ratio, and incubated for an additional $30 \mathrm{~min}$ on ice. The reaction was loaded on two tandem Superdex S200 columns equilibrated with Buffer C. Peak fractions containing $\mathrm{Ga}_{\mathrm{q}}-\mathrm{PLC} \beta 3$ were pooled and concentrated in a $100 \mathrm{kDa}$ Amicon concentrator.

\section{Crystallization and Structure Determination of the $\mathrm{Ga}_{\mathrm{q}}-\mathrm{PLC} \beta 3$ Complex}

$\mathrm{Ga}_{\mathrm{q}}-\mathrm{PLC} \beta 3$ was suspended in hanging drops containing $1 \mu \mathrm{Ga} \mathrm{q}_{\mathrm{q}}-\mathrm{PLC} \beta 3$ at $6.2 \mathrm{mg} \mathrm{ml}^{-1}$ mixed with $1 \mu \mathrm{l}$ well solution. The well solution contained $100 \mathrm{mM}$ MES pH 6.75, 100-200 $\mathrm{mM} \mathrm{NaCl}$, and 11-12\% PEG 3350, with crystals appearing in 4-7 d at $4{ }^{\circ} \mathrm{C}$. Crystals were harvested in $20 \mathrm{mM}$ HEPES pH 8, 400-500 mM NaCl, 2 M DTT, $0.9 \mathrm{mM} \mathrm{CaCl}_{2}, 5 \mathrm{mM}$ $\mathrm{MgCl}_{2}, 10 \mathrm{mM} \mathrm{NaF}, 30 \mu \mathrm{M} \mathrm{AlCl} 3,50 \mu \mathrm{M} \mathrm{GDP}, 15 \%$ (w/v) PEG 3350, and 30\% (v/v) 1,3butanediol, then frozen on nylon loops in liquid nitrogen for data collection.

Diffraction data was collected at the Advanced Photon Source at LS-CAT Beam line 21-ID$\mathrm{D}$ and GM/CA-CAT beam line 23-ID-D from crystals maintained at $110 \mathrm{~K}$ at wavelengths of $1.13 \AA$ and $1.03 \AA$ respectively. Although initial diffraction to $3.3 \AA$ spacings was observed, rapid decay limited useful data to $4.0 \AA$ A spacings (Table 1). Data sets were reduced using $\mathrm{HKL} 2000^{48}$, and initial phases were derived by molecular replacement using the $3 \mathrm{OHM}$ structure ${ }^{18}$ as a search model. Models were refined via restrained refinement with TLS using the program REFMAC5 ${ }^{49}$. Five TLS groups were used: one for each $\mathrm{Ga}_{\mathrm{q}}$ chain, its ligands ( $\mathrm{Mg}^{2+}, \mathrm{GDP}$, and $\mathrm{AlF}_{4}{ }^{-}$molecules) and its bound $\mathrm{PLC} \beta 3$ proximal CTD (residues 863-881), one for each PLC $\beta 3$ catalytic core and its associated $\mathrm{Ca}^{2+}$ atom, and one 
for the distal CTD. NCS restraints were imposed on the two $\mathrm{Ga}_{\mathrm{q}}$ chains (residues 39-353 and its ligands) and the two PLC $\beta 3$ chains (residues 16-194, 202-862, and the $\mathrm{Ca}^{2+}$ atoms). Stereochemical correctness of the final model was assessed with MolProbity ${ }^{50}$. In the final model, $94.7 \%$ of residues were in favored regions of the Ramachandran plot, $4.9 \%$ of residues in allowed regions, and $0.4 \%$ in disallowed regions. Residues in disallowed regions were also observed the $2.7 \AA \mathrm{Ga}_{\mathrm{q}}-\mathrm{PLC} \beta 3-\Delta 887$ structure $^{18}$. Electron density was observed for residues 11-470 and 573-881 in chain A of PLC $\beta 3$, and 10-196, 199-470, and 575-881 in the second. Residues 471-572 correspond to a region of the X-Y linker that has low sequence homology and is typically poorly ordered ${ }^{18,19,40,43}$. In the distal CTD, the Da3Da4 (residues 1009-1025) and Da4-Da5 (residues 1108-1114) loops and C-terminal residues 1193-1234 lacked electron density, consistent with being disordered (Supplementary Fig. 3a). In $\mathrm{Ga}_{\mathrm{q}}$, electron density was observed for residues 18-354 in the first molecule and 35-355 in the second.

\section{Cryo-EM Sample Preparation and Imaging}

$3 \mu$ of purified $\mathrm{Ga}_{\mathrm{q}}-\mathrm{PLC} \beta 3$ was adsorbed on glow-discharged Quantifoil R2/2 200 mesh grids, and vitrified using a Vitrobot (FEI Mark IV). The specimen was imaged on a Tecnai F20 transmission electron microscope (FEI) equipped with a field emission gun and operated at $120 \mathrm{kV}$. Images were recorded at a magnification of $71,138 \mathrm{x}$ on a Gatan US4000 $\mathrm{CCD}$ camera and defocus values ranging from -2 to $-3 \mu \mathrm{m}$. All images were binned $(2 \times 2$ pixels) to obtain a pixel size of $4.48 \AA$ on the specimen level.

\section{Cryo-EM 3D reconstructions and molecular modeling}

40,124 particle projections from $\mathrm{Ga}_{\mathrm{q}}-\mathrm{PLC} \beta 3$ images were interactively selected and excised using Boxer (EMAN 1.9 software suite) ${ }^{51}$. The CTF parameters for each micrograph were determined using ctfit, and CTF correction was applied accordingly using the program Applyctf (part of EMAN 1.9 package). Multiple 3D reference-supervised classification was applied to the data set, using four possible models of the complex observed in the crystal lattice. These unique particle datasets were used to calculate four independent 3D reconstructions using the same initial reference of the $\mathrm{Ga}_{\mathrm{q}}-\mathrm{PLC} \beta 3$ core but lacking the distal CTD. $20 \AA$-filtered volumes of $\mathrm{Ga}_{\mathrm{q}}-\mathrm{PLC} \beta 3$ structures observed in the crystal lattice were computationally fitted as rigid bodies in the EM maps and cross-correlation values obtained using Chimera $^{52}$. For a more detailed description, see Supplementary Note.

\section{PLC $\beta 3$ activity assays}

PLC $\beta 3$ basal and $\mathrm{Ga}_{\mathrm{q}}$-stimulated activity was determined by measuring the amount of free $\left[{ }^{3} \mathrm{H}\right]-\mathrm{IP}_{3}$ released from $\left[{ }^{3} \mathrm{H}\right]-\mathrm{PIP}_{2}$-containing liposomes, as previously described ${ }^{19,53}$. PLC $\beta 3$ variants were assayed at a final concentration that resulted in activity within the linear range over the time course of the experiment. PLC $\beta 3$, PLC $\beta 3$ EEE, and PLC $\beta 3-\triangle 882-937$ were

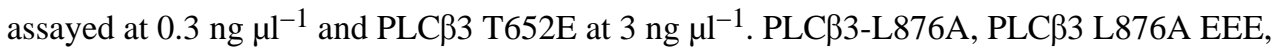

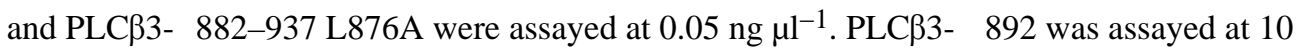
ng $\mu \mathrm{l}^{-1}$ and PLC $\beta 3-\triangle 892 \mathrm{~T} 652 \mathrm{E}$ at $20 \mathrm{ng} \mu \mathrm{l}^{-1}$. 


\section{Flow Cytometry Protein Interaction Assay (FCPIA)}

Equilibrium binding of PLC $\beta 3$ variants to $\mathrm{Ga}_{\mathrm{q}}$ variants was measured using FCPIA as described previously ${ }^{19}$, wherein a PLC $\beta 3$ variant with high affinity for $\mathrm{Ga}_{\mathrm{q}}(\mathrm{PLC} \beta 3-\Delta 892$ R872A L876A L879A) ${ }^{19}$ was fluorescently labeled with Alexa-Fluor-488 (AF488) $\mathrm{C}_{5}{ }^{-}$ maleimide (Invitrogen). $\mathrm{Ga}_{\mathrm{q}}$ proteins were biotinylated $\left(\mathrm{b}-\mathrm{Ga}_{\mathrm{q}}\right)^{19,54}$ and linked to SPHERO Streptavidin Coated Particles (Spherotech). Unlabeled PLC $\beta 3$ variants were added to the bead-bound $\mathrm{b}-\mathrm{Ga}_{\mathrm{q}}$ proteins over a range of concentrations, after which AF488-labeled PLC $\beta 3-\triangle 892$ R872A L876A L879A was added at its measured $K_{\mathrm{D}}(40 \mathrm{nM})$ and incubated for $1 \mathrm{~h}$ prior to being processed with an Accuri C6 flow cytometer ${ }^{19}$.

\section{Detection of Palmitoylated $\mathrm{Ga}_{\mathrm{q}}$}

Purified His-tagged $\mathrm{Ga}_{\mathrm{q}}$ variants at identical concentrations were diluted to a final volume of $400 \mu \mathrm{l}$ in $50 \mathrm{mM}$ HEPES pH 7.5, $150 \mathrm{mM} \mathrm{NaCl}, 1 \%$ Triton X-100, $25 \mathrm{mM} \mathrm{N}-$ ethylmaleimide (USB), protease inhibitors, and $0.1 \%$ SDS, then rotated overnight at $4{ }^{\circ} \mathrm{C}$ with $35 \mu \mathrm{l} \mathrm{Ni-NTA}$ beads. Samples were divided in half, with controls incubated with $0.5 \mathrm{M}$ HEPES pH 7.5, and all other samples with $0.25 \mathrm{M}$ HEPES $\mathrm{pH} 8$ and $0.25 \mathrm{M}$ hydroxylamine (Sigma-Aldrich). Samples were incubated and rocked for $4 \mathrm{~h}$ at room temperature. Ni-NTA beads were washed twice with PBS, and resuspended in $225 \mu \mathrm{l}$ PBS. Samples were treated with $0.4 \mathrm{mM} \mathrm{N}$-[6-(biotinamido)hexyl]-3'-(2'-pyridyldithio)propionamide (HPDP-biotin, Thermo Scientific) and incubated and rocked for $2 \mathrm{~h}$ at room temperature. Beads were washed once with PBS, and resuspended in SDS loading dye. Protection of cysteines via palmitoylation was then detected by western blot using a biotin antibody (StrepTactin-HRP Conjugate at 1:10,000 dilution, Biorad) ${ }^{55,56}$.

\section{Multi-Angle Light Scattering}

Purified PLC $\beta 3$ or $\mathrm{Ga}_{\mathrm{q}}-\mathrm{PLC} \beta 3$ were filtered and applied to a 50S size exclusion column with a molecular weight range of 15,000-5,000,000 Da connected to multi-angle wavelength detector (Wyatt Technology). The system was equilibrated with either PLC $\beta 3$ Buffer A (20 mM HEPES pH 8, $200 \mathrm{mM} \mathrm{NaCl}, 2 \mathrm{mM}$ DTT, $0.1 \mathrm{mM}$ EGTA, and $0.1 \mathrm{mM}$ EDTA), or $\mathrm{Ga}_{\mathrm{q}}-\mathrm{PLC} \beta 3$ Buffer C. The molecular weights of PLC $\beta 3$ and $\mathrm{Ga}_{\mathrm{q}}-\mathrm{PLC} \beta 3$ were determined by fitting the elution peak of the protein using ASTRA software.

\section{Statistical Methods}

Statistical analyses used analysis of variance (ANOVA) with a Tukey's post test as implemented in Prism (version 5.0a). All comparisons deemed significant had P values of at least $<0.01$.

Figures. Structure images were generated using Pymol Version 1.5.0 (Schrödinger, LLC), and electrostatic surfaces were calculated using $\mathrm{APBS}^{57}$. Figures were created using Adobe ${ }^{\circledR}$ Photoshop and Illustrator.

\section{Supplementary Material}

Refer to Web version on PubMed Central for supplementary material. 


\section{ACKNOWLEDGMENTS}

We thank D. Southworth (Life Sciences Institute, University of Michigan) for help with light scattering experiments. This work was supported by National Institutes of Health (NIH) grants HL086865, HL071818 and GM081655 (J.J.G.T), NIH grant DK090165 and the University of Michigan Biological Sciences Scholars Program (G.S.) and an American Heart Association Post-Doctoral Fellowship (A.M.L.). G.S. is a Pew Scholar of Biomedical Sciences. This work used the Cell and Molecular Biology Core of the Michigan Diabetes Research and Training Center, supported by DK20572. This research was supported in part by the National Institutes of Health through the University of Michigan Cancer Center Support Grant (P30 CA046592). Use of LS-CAT Sector 21 was supported by the Michigan Economic Development Corporation and Michigan's Technology Tri-Corridor (grant 085P100817). Use of GM/CA at the Advanced Photon Source at Argonne National Laboratory has been funded in whole or in part with federal funds from the National Cancer Institute (Y1-CO-1020) and the National Institute of General Medical Services (Y1-GM-1104). Use of the Advanced Photon Source at Argonne National Laboratory was supported by the US Department of Energy, Office of Science, Office of Basic Energy Sciences, under contract no. DE-AC02-06CH11357.

\section{REFERENCES}

1. Gresset A, Sondek J, Harden TK. The phospholipase C isozymes and their regulation. Subcell Biochem. 2012; 58:61-94. [PubMed: 22403074]

2. Kadamur G, Ross EM. Mammalian phospholipase C. Annu Rev Physiol. 2012 Epub ahead of print.

3. Taylor SJ, Chae HZ, Rhee SG, Exton JH. Activation of the $\beta 1$ isozyme of phospholipase $\mathrm{C}$ by a subunits of the $\mathrm{G}_{\mathrm{q}}$ class of $\mathrm{G}$ proteins. Nature. 1991; 350:516-518. [PubMed: 1707501]

4. Smrcka AV, Sternweis PC. Regulation of purified subtypes of phosphatidylinositol-specific phospholipase $\mathrm{C} \beta$ by G protein $\alpha$ and $\beta \gamma$ subunits. J Biol Chem. 1993; 268:9667-9674. [PubMed: 8387502]

5. Smrcka AV, Hepler JR, Brown KO, Sternweis PC. Regulation of polyphosphoinositide-specific phospholipase C activity by purified $\mathrm{G}_{\mathrm{q}}$. Science. 1991; 251:804-807. [PubMed: 1846707]

6. Jiang H, et al. Roles of phospholipase $\mathrm{C} \beta 2$ in chemoattractant-elicited responses. Proc Natl Acad Sci U S A. 1997; 94:7971-7975. [PubMed: 9223297]

7. Kim D, et al. Phospholipase C isozymes selectively couple to specific neurotransmitter receptors. Nature. 1997; 389:290-293. [PubMed: 9305844]

8. Xie W, et al. Genetic alteration of phospholipase C $\beta 3$ expression modulates behavioral and cellular responses to $\mu$ opioids. Proc Natl Acad Sci U S A. 1999; 96:10385-10390. [PubMed: 10468617]

9. Van Raamsdonk CD, et al. Frequent somatic mutations of GNAQ in uveal melanoma and blue naevi. Nature. 2009; 457:599-602. [PubMed: 19078957]

10. Descorbeth M, Anand-Srivastava MB. High glucose increases the expression of $G_{q / 11} \alpha$ and PLC $\beta$ proteins and associated signaling in vascular smooth muscle cells. Am J Physiol Heart Circ Physiol. 2008; 295:H2135-H2142. [PubMed: 18820027]

11. Descorbeth M, Anand-Srivastava MB. Role of growth factor receptor transactivation in high glucose-induced increased levels of $\mathrm{G}_{\mathrm{q} / 11} \mathrm{a}$ and signaling in vascular smooth muscle cells. J Mol Cell Cardiol. 2010; 49:221-233. [PubMed: 20036247]

12. Ushio-Fukai M, Griendling KK, Akers M, Lyons PR, Alexander RW. Temporal dispersion of activation of phospholipase $\mathrm{C}-\beta 1$ and $-\gamma$ isoforms by angiotensin II in vascular smooth muscle cells. Role of $\alpha_{\mathrm{q} / 11}, \alpha_{12}$, and $\beta \gamma \mathrm{G}$ protein subunits. J Biol Chem. 1998; 273:19772-19777. [PubMed: 9677408]

13. Woodcock EA, Kistler PM, Ju Y-K. Phosphoinositide signalling and cardiac arrhythmias. Cardiovasc. Res. 2009; 82:286-295. [PubMed: 18940816]

14. Grubb DR, Vasilevski O, Huynh H, Woodcock EA. The extreme C-terminal region of phospholipase $C \beta 1$ determines subcellular localization and function; the "b" splice variant mediates $a_{1}$-adrenergic receptor responses in cardiomyocytes. FASEB J. 2008; 22:2768-2774. [PubMed: 18390926]

15. Filtz TM, Grubb DR, McLeod-Dryden TJ, Luo J, Woodcock EA. $\mathrm{G}_{\mathrm{q}}$-initiated cardiomyocyte hypertrophy is mediated by phospholipase C $\beta 1$ b. FASEB J. 2009; 23:3564-3570. [PubMed: 19564249] 
16. Dent MR, Dhalla NS, Tappia PS. Phospholipase C gene expression, protein content, and activities in cardiac hypertrophy and heart failure due to volume overload. Am J Physiol Heart Circ Physiol. 2004; 287:H719-H727. [PubMed: 15072958]

17. Woodcock EA, Grubb DR, Iliades P. Potential treatment of cardiac hypertrophy and heart failure by inhibiting the sarcolemmal binding of phospholipase C $\beta 1$ b. Curr Drug Targets. 2010; 11:10321040. [PubMed: 20426766]

18. Waldo GL, et al. Kinetic scaffolding mediated by a phospholipase C- $\beta$ and $\mathrm{G}_{\mathrm{q}}$ signaling complex. Science. 2010; 330:974-980. [PubMed: 20966218]

19. Lyon AM, et al. An autoinhibitory helix in the C-terminal region of phospholipase C- $\beta$ mediates $\mathrm{Ga}_{\mathrm{q}}$ activation. Nat Struct Mol Biol. 2011; 18:999-1005. [PubMed: 21822282]

20. Lee S, Shin S, Hepler J, Gilman A, Rhee S. Activation of phospholipase C- $\beta 2$ mutants by G protein $\alpha_{\mathrm{q}}$ and $\beta \gamma$ subunits. J Biol Chem. 1993; 268:25952-25957. [PubMed: 8245028]

21. Kim CG, Park D, Rhee SG. The role of carboxyl-terminal basic amino acids in $\mathrm{G}_{\mathrm{q}} \mathrm{a}$-dependent activation, particulate association, and nuclear localization of phospholipase C- $\beta 1$. J Biol Chem. 1996; 271:21187-21192. [PubMed: 8702889]

22. Park D, Jhon DY, Lee CW, Ryu SH, Rhee SG. Removal of the carboxyl-terminal region of phospholipase C- $\beta 1$ by calpain abolishes activation by $\mathrm{Ga}_{\mathrm{q}}$. J Biol Chem. 1993; 268:3710-3714. [PubMed: 8429045]

23. Wu D, Jiang H, Katz A, Simon MI. Identification of critical regions on phospholipase C- $\beta 1$ required for activation by G-proteins. J Biol Chem. 1993; 268:3704-3709. [PubMed: 8381437]

24. Schnabel P, Camps M, Carozzi A, Parker PJ, Gierschik P. Mutational analysis of phospholipase C$\beta 2$. Identification of regions required for membrane association and stimulation by guaninenucleotide-binding protein $\beta \gamma$ subunits. Eur J Biochem. 1993; 217:1109-1115. [PubMed: 8223634]

25. Jenco JM, Becker KP, Morris AJ. Membrane-binding properties of phospholipase C- $\beta 1$ and phospholipase $\mathrm{C}-\beta 2$ : role of the $\mathrm{C}$-terminus and effects of polyphosphoinositides, G-proteins and $\mathrm{Ca}^{2+}$ Biochem J. 1997; 327((Pt 2)):431-437. [PubMed: 9359412]

26. Singer AU, Waldo GL, Harden TK, Sondek J. A unique fold of phospholipase C- $\beta$ mediates dimerization and interaction with $\mathrm{Ga}_{\mathrm{q}}$. Nat Struct Biol. 2002; 9:32-36. [PubMed: 11753430]

27. Ilkaeva O, Kinch LN, Paulssen RH, Ross EM. Mutations in the carboxyl-terminal domain of phospholipase $\mathrm{C}-\beta 1$ delineate the dimer interface and a potential $\mathrm{Ga}_{\mathrm{q}}$ interaction site. $\mathrm{J}$ Biol Chem. 2002; 277:4294-4300. [PubMed: 11729196]

28. Adjobo-Hermans MJ, Goedhart J, Gadella TW Jr. Regulation of PLC $\beta 1$ a membrane anchoring by its substrate phosphatidylinositol (4,5)-bisphosphate. J Cell Sci. 2008; 121:3770-3777. [PubMed: 18957514]

29. Adjobo-Hermans MJ, et al. PLC $\beta$ isoforms differ in their subcellular location and their CT-domain dependent interaction with $\mathrm{Ga}_{\mathrm{q}}$. Cell Signal. 2013; 25:255-263. [PubMed: 23006664]

30. Chothia C, Lesk AM. The relation between the divergence of sequence and structure in proteins. EMBO J. 1986; 5:823-826. [PubMed: 3709526]

31. Holm L, Rosenstrom P. Dali server: conservation mapping in 3D. Nucleic Acids Res. 2010; 38:W545-W549. [PubMed: 20457744]

32. Romoser V, Ball R, Smrcka AV. Phospholipase C $\beta 2$ association with phospholipid interfaces assessed by fluorescence resonance energy transfer. G protein betagamma subunit-mediated translocation is not required for enzyme activation. J Biol Chem. 1996; 271:25071-25078. [PubMed: 8810260]

33. Qualmann B, Koch D, Kessels MM. Let's go bananas: revisiting the endocytic BAR code. EMBO J. 2011; 30:3501-3515. [PubMed: 21878992]

34. Antonny B. Mechanisms of membrane curvature sensing. Annu Rev Biochem. 2011; 80:101-123. [PubMed: 21438688]

35. Peter BJ, et al. BAR domains as sensors of membrane curvature: the amphiphysin BAR structure. Science. 2004; 303:495-499. [PubMed: 14645856]

36. Essen LO, Perisic O, Cheung R, Katan M, Williams RL. Crystal structure of a mammalian phosphoinositide-specific phospholipase C $\delta$. Nature. 1996; 380:595-602. [PubMed: 8602259] 
37. Ellis MV, et al. Catalytic domain of phosphoinositide-specific phospholipase C (PLC). Mutational analysis of residues within the active site and hydrophobic ridge of PLC $\delta 1$. J Biol Chem. 1998; 273:11650-11659. [PubMed: 9565585]

38. Hepler JR, et al. Functional importance of the amino terminus of $\mathrm{G}_{\mathrm{q}}$ a. J Biol Chem. 1996; 271:496-504. [PubMed: 8550609]

39. Nomura S, Fukaya M, Tsujioka T, Wu D, Watanabe M. Phospholipase C $\beta 3$ is distributed in both somatodendritic and axonal compartments and localized around perisynapse and smooth endoplasmic reticulum in mouse Purkinje cell subsets. Eur J Neurosci. 2007; 25:659-672. [PubMed: 17298601]

40. Hicks SN, et al. General and versatile autoinhibition of PLC isozymes. Mol Cell. 2008; 31:383394. [PubMed: 18691970]

41. Boyer JL, Waldo GL, Harden TK. $\beta \gamma$-subunit activation of G-protein-regulated phospholipase C. J Biol Chem. 1992; 267:25451-25456. [PubMed: 1460039]

42. Illenberger D, et al. Stimulation of phospholipase C- $\beta 2$ by the Rho GTPases Cdc42Hs and Rac1. EMBO J. 1998; 17:6241-6249. [PubMed: 9799233]

43. Jezyk MR, et al. Crystal structure of Rac1 bound to its effector phospholipase C- $\beta 2$. Nat Struct Mol Biol. 2006; 13:1135-1140. [PubMed: 17115053]

44. Han DS, Golebiewska U, Stolzenberg S, Scarlata SF, Weinstein H. A dynamic model of membrane-bound phospholipase C $\beta 2$ activation by G $\beta \gamma$ subunits. Mol Pharmacol. 2011; 80:434445. [PubMed: 21693623]

45. Philip F, Kadamur G, Silos RG, Woodson J, Ross EM. Synergistic activation of phospholipase C$\beta 3$ by $\mathrm{Ga}_{\mathrm{q}}$ and $\mathrm{G} \beta \gamma$ describes a simple two-state coincidence detector. Curr Biol. 2010; 20:13271335. [PubMed: 20579885]

46. Rebres RA, et al. Synergistic $\mathrm{Ca}^{2+}$ responses by $\mathrm{Ga}_{\mathrm{i}}$ - and $\mathrm{Ga}_{\mathrm{q}}$-coupled $\mathrm{G}$-protein-coupled receptors require a single PLC $\beta$ isoform that is sensitive to both $\mathrm{G} \beta \gamma$ and $\mathrm{Ga}_{\mathrm{q}}$. J Biol Chem. 2011; 286:942-951. [PubMed: 21036901]

47. Wang T, Pentyala S, Rebecchi MJ, Scarlata S. Differential association of the pleckstrin homology domains of phospholipases C- $\beta 1, C-\beta 2$, and C- $\delta 1$ with lipid bilayers and the $\beta \gamma$ subunits of heterotrimeric G proteins. Biochemistry. 1999; 38:1517-1524. [PubMed: 9931017]

\section{Methods-Only-References}

48. Otwinowski Z, Minor W. Processing of X-ray diffraction data collected in oscillation mode. Macromolecular Crystallography, Pt A. 1997; 276:307-326.

49. Winn MD, Murshudov GN, Papiz MZ. Macromolecular TLS refinement in REFMAC at moderate resolutions. Methods Enzymol. 2003; 374:300-321. [PubMed: 14696379]

50. Davis IW, et al. MolProbity: all-atom contacts and structure validation for proteins and nucleic acids. Nucleic Acids Res. 2007; 35:W375-W383. [PubMed: 17452350]

51. Ludtke SJ, Baldwin PR, Chiu W. EMAN: semiautomated software for high-resolution singleparticle reconstructions. J Struct Biol. 1999; 128:82-97. [PubMed: 10600563]

52. Pettersen EF, et al. UCSF Chimera--a visualization system for exploratory research and analysis. J Comput Chem. 2004; 25:1605-1612. [PubMed: 15264254]

53. Ghosh M, Smrcka AV. Assay for G protein-dependent activation of phospholipase $\mathrm{C} \beta$ using purified protein components. Methods Mol Biol. 2004; 237:67-75. [PubMed: 14501039]

54. Shankaranarayanan A, et al. Assembly of high order $\mathrm{Ga}_{\mathrm{q}}$-effector complexes with RGS proteins. J Biol Chem. 2008; 283:34923-34924. [PubMed: 18936096]

55. Drisdel RC, Green WN. Labeling and quantifying sites of protein palmitoylation. Biotechniques. 2004; 36:276-285. [PubMed: 14989092]

56. Linder ME, Deschenes RJ. Palmitoylation: policing protein stability and traffic. Nat Rev Mol Cell Biol. 2007; 8:74-84. [PubMed: 17183362]

57. Baker NA, Sept D, Joseph S, Holst MJ, McCammon JA. Electrostatics of nanosystems: application to microtubules and the ribosome. Proc Natl Acad Sci U S A. 2001; 98:10037-10041. [PubMed: $11517324]$ 

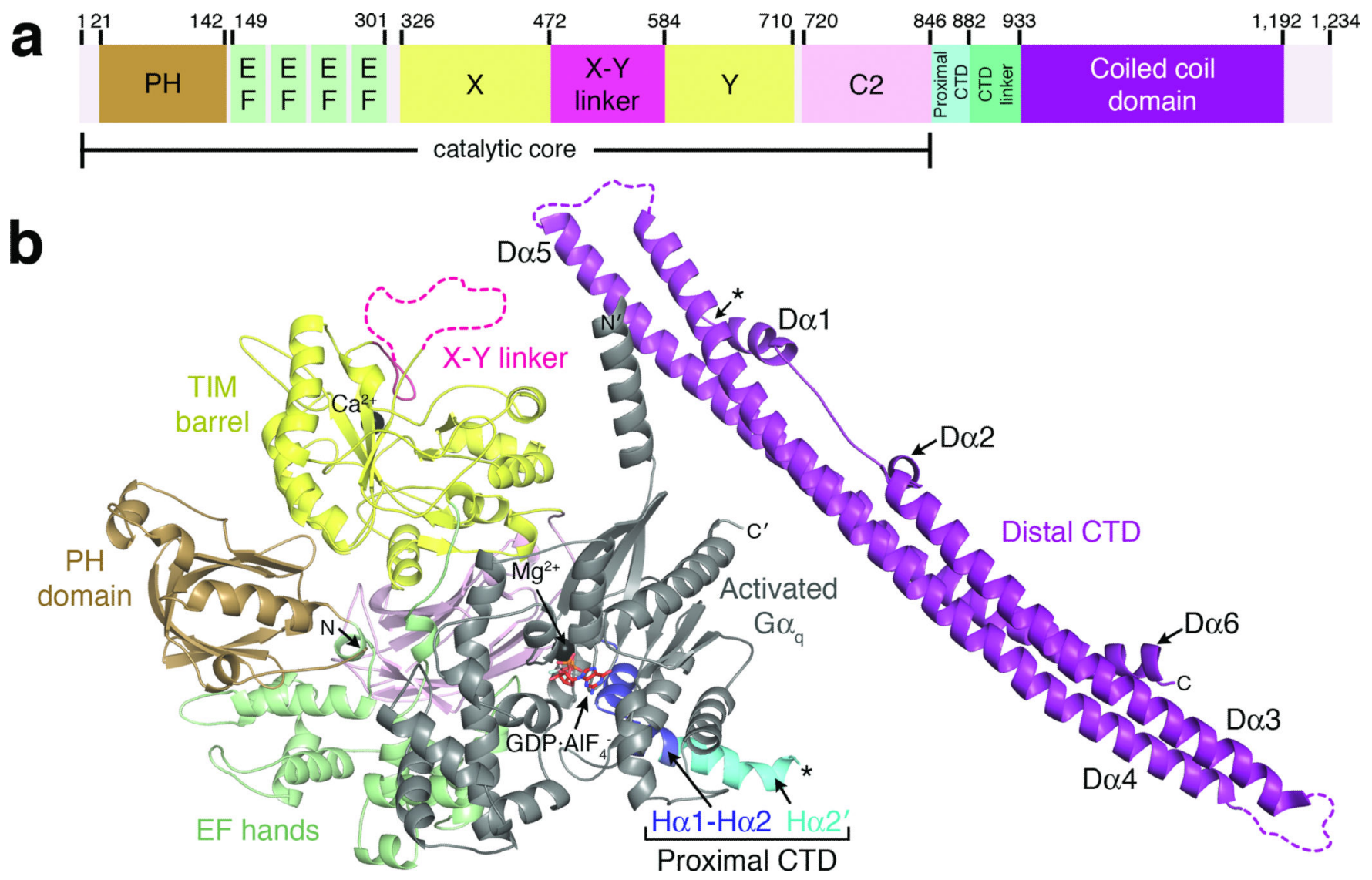

Figure 1.

Crystal structure of $\mathrm{Ga}_{\mathrm{q}}-\mathrm{PLC} \beta 3$ reveals the $\mathrm{C}$-terminal coiled-coil domain (distal CTD) in the context of a fully active signaling complex. (a) Primary structure of human PLC $\beta 3$. Numbers above the diagram correspond to domain boundaries. The catalytic core of the enzyme is defined as extending from the $\mathrm{N}$-terminus to the end of the $\mathrm{C} 2$ domain. (b) A monomer of $\mathrm{Ga}_{\mathrm{q}}-\mathrm{PLC} \beta 3$ from the asymmetric unit. Domains of PLC $\beta 3$ are colored as in (a). The observed C-terminus of the proximal CTD and the N-terminus of the distal CTD are marked with black asterisks, although this represents only one possible linkage between the catalytic core and distal CTD in the crystal lattice (see Supplementary Fig. 4). The observed $\mathrm{N}$ and C-termini of PLC $\beta 3$ and $\mathrm{Ga}_{\mathrm{q}}$ are labeled $\mathrm{N}$ and $\mathrm{C}$, and $\mathrm{N}^{\prime}$ and $\mathrm{C}^{\prime}$, respectively. $\mathrm{Ca}^{2+}$ and $\mathrm{Mg}^{2+}$ are shown as black spheres. Activated $\mathrm{Ga}_{\mathrm{q}}$ is shown in gray, with bound GDP and $\mathrm{AlF}_{4}{ }^{-}$drawn as red sticks. Dashed lines correspond to disordered loops. 


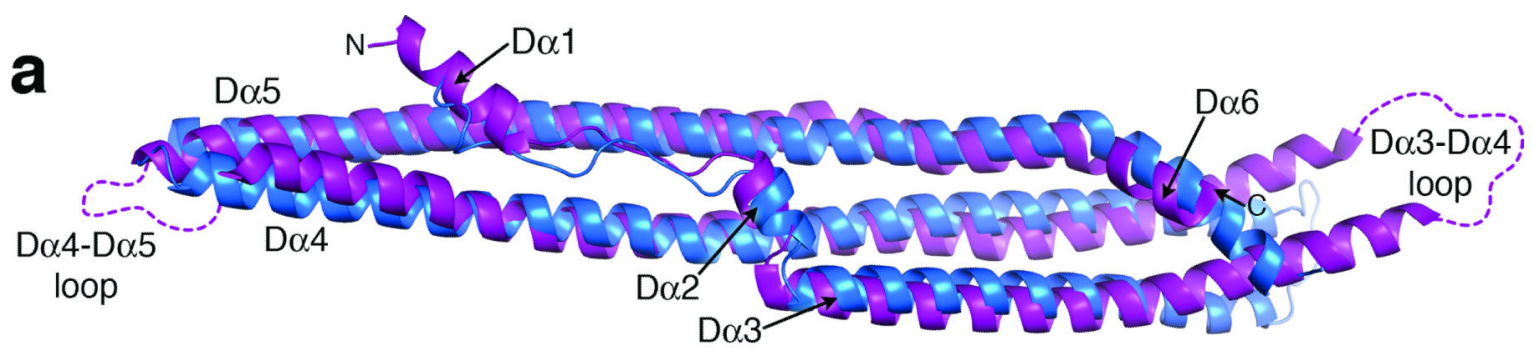

b

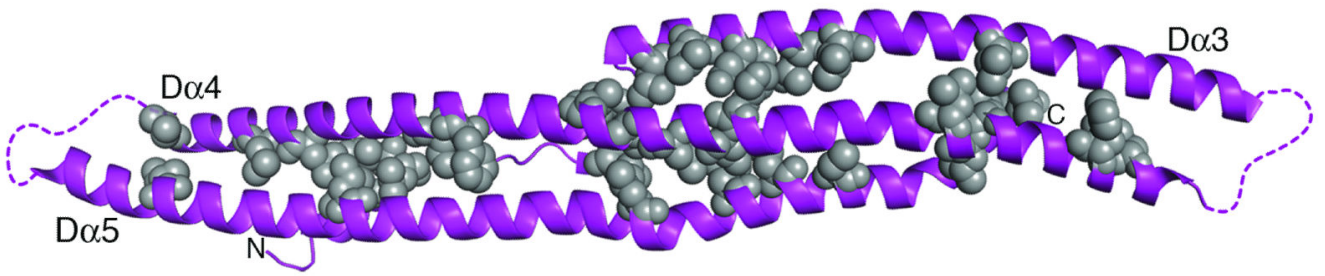

C

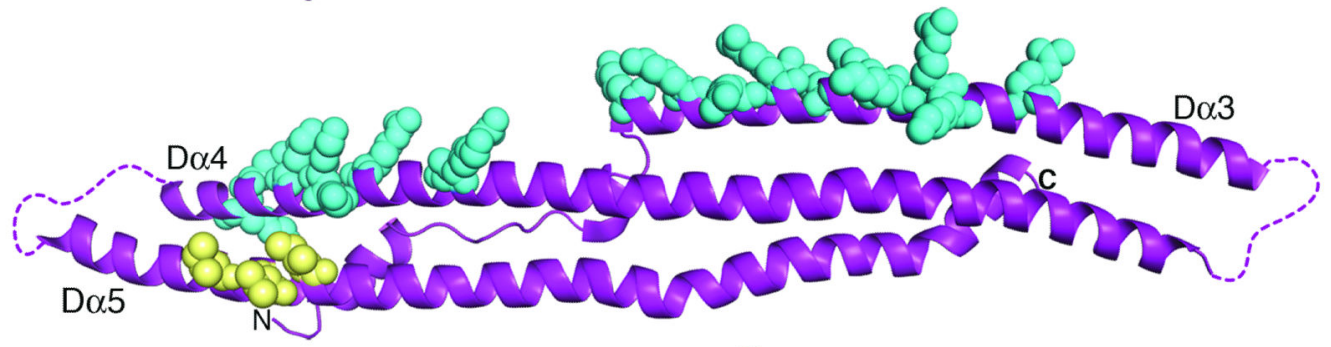

d

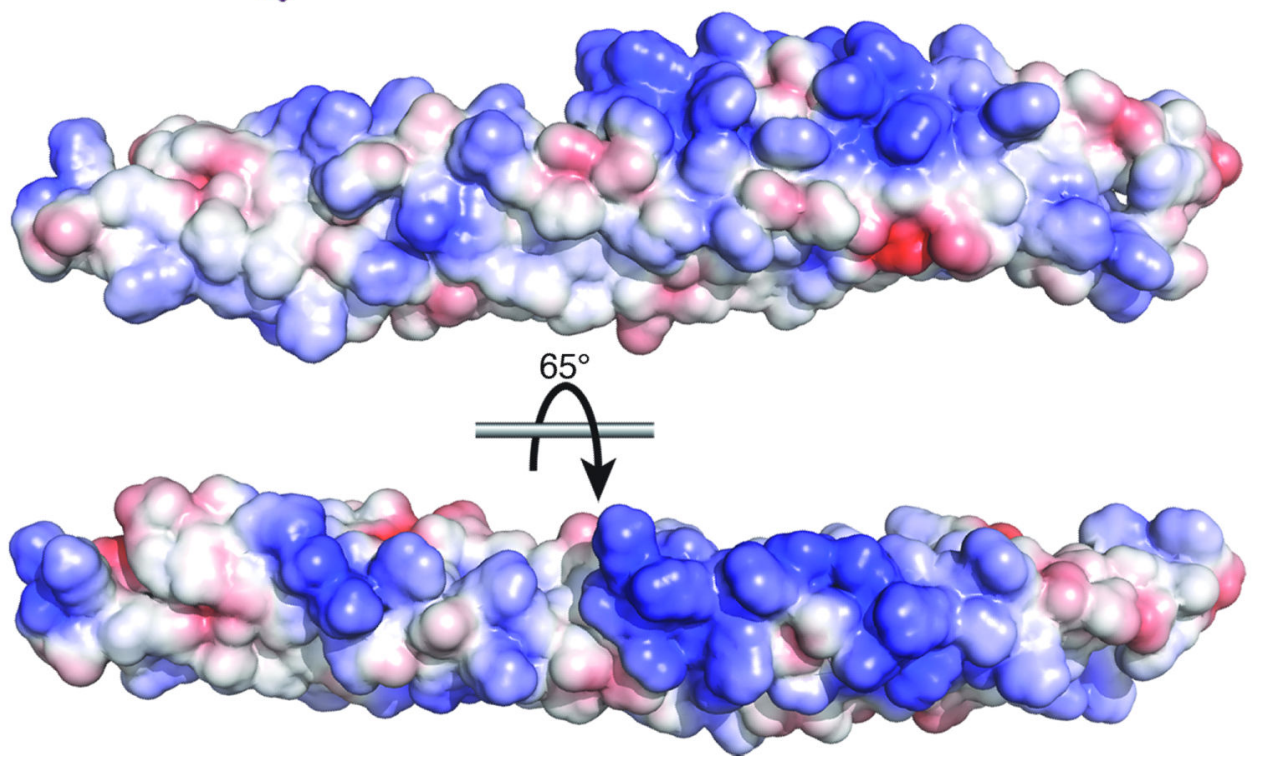

Figure 2.

Structural comparison and sequence conservation of the PLC $\beta$ distal CTD. (a) Superposition of the distal CTDs from PLC $\beta 3$ (purple) and turkey PLC $\beta$ (blue) ${ }^{26}$. Although they have the same fold, they differ substantially in conformation in that the PLC $\beta 3$ distal CTD is more curved. Disordered loops within the distal CTD are marked as dashed lines. (b) The distal CTD is stabilized by conserved hydrophobic residues (gray spheres) that pack between the three segments of the domain (see Supplementary Fig. 1). The view is from the opposite side of the domain as shown in panel (a), rotated around a horizontal axis. (c) The distal CTD has 
two conserved, solvent-exposed regions: a basic ridge along Da3 and Da4 (blue spheres), and a hydrophobic patch on Da5 (yellow spheres). In our structure the hydrophobic patch interacts with the N-terminus of $\mathrm{Ga}_{\mathrm{q}}$ (see Fig. $1 \mathrm{~b}$ and Fig. $4 \mathrm{a}, \mathrm{c}$ ). (d) Electrostatic surface of the distal CTD. The top image corresponds to the same view as in (b). The surface is colored from $-4 \mathrm{kT} \cdot \mathrm{e}^{-1}$ (red) to $+4 \mathrm{kT} \cdot \mathrm{e}^{-1}$ (blue). 

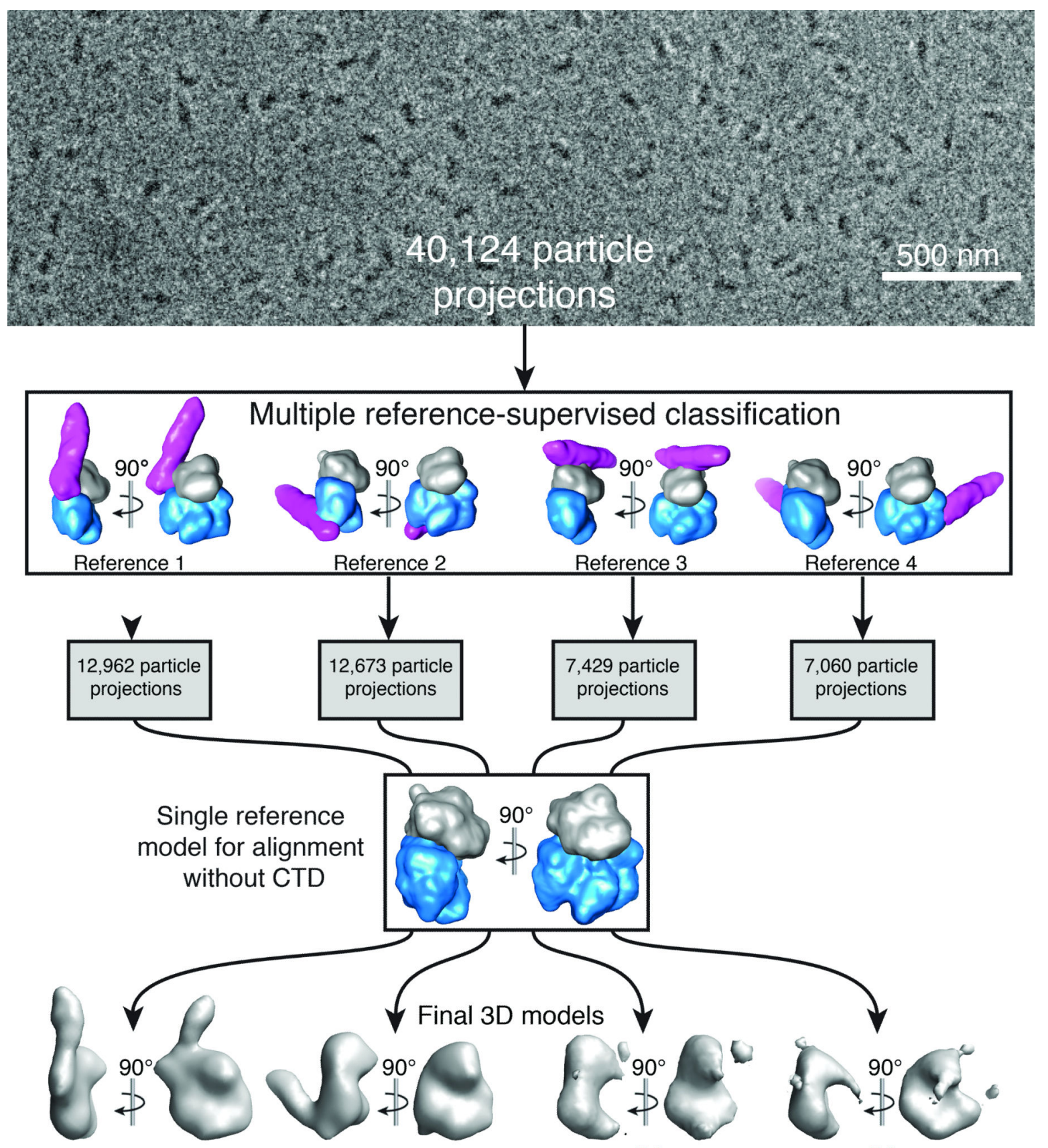
2,962 particle
projections

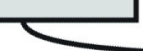

Reference 4

Figure 3.

Cryo-EM projection classification and 3D reconstruction scheme. 40,124 particle projections were subjected to multiple $3 \mathrm{D}$ reference-supervised classification against volumes of four $\mathrm{Ga}_{\mathrm{q}}-\mathrm{PLC} \beta 3$ core complexes observed in the crystal lattice. The density corresponding to $\mathrm{Ga}_{\mathrm{q}}$ is shown in gray, the PLC $\beta 3$ core in blue, and the distal CTD in purple. Each group of particles was used to generate a unique $3 \mathrm{D}$ reconstruction using the $\mathrm{Ga}_{\mathrm{q}}-\mathrm{PLC} \beta 3$ structure, omitting the distal CTD, as the initial reference. Two final 3D reconstructions were of good quality as judged by the definition of the $\mathrm{Ga}_{\mathrm{q}}-\mathrm{PLC} \beta 3$ core 
complex (green stars). In the first model the distal CTD is docked with the N-terminal helix of $\mathrm{Ga}_{\mathrm{q}}$, and in the second with the hydrophobic ridge of the catalytic core of PLC $\beta 3$. The third represents a contact between the Da3-Da4 loop of the distal CTD and the second EF hand (Ea2 and $\mathrm{Fa} 2$ helices) of the catalytic core. The fourth model represents an interaction between the distal CTD and the Ras-like domain of $\mathrm{Ga}_{\mathrm{q}}$ (Supplementary Fig. 2d). Based on functional analysis (Table 2) and failure to obtain reliable reconstructions, the last two interactions (models 3 and 4) likely represent simple lattice contacts. A representative cryoEM image of purified $\mathrm{Ga}_{\mathrm{q}}-\mathrm{PLC} \beta 3$ complexes is shown at the top of the figure. 
a
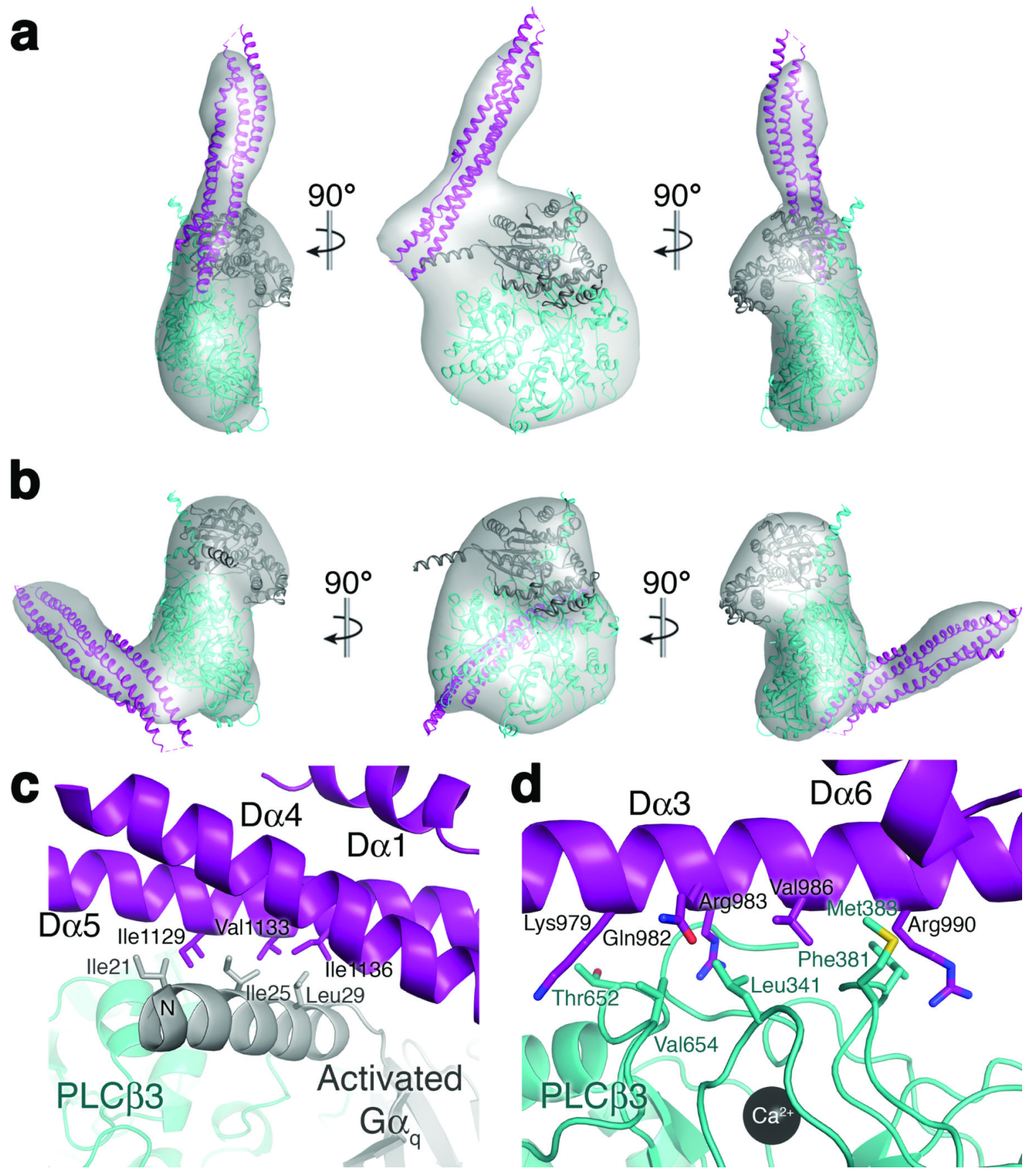

Figure 4.

The distal CTD interacts with the N-terminal helix of $\mathrm{Ga}_{\mathrm{q}}$ and the PLC $\beta 3$ catalytic core in solution and in crystals. (a) A $19 \AA$ 3 D EM reconstruction with docked crystal structure of the distal CTD in complex with the $\mathrm{N}$-terminal helix of $\mathrm{Ga}_{\mathrm{q}}$. The distal CTD is shown in purple, the PLC $\beta 3$ core in teal, and $\mathrm{Ga}_{\mathrm{q}}$ in gray. (b) A $21 \AA$ 3D reconstruction with docked crystal structure of the distal CTD in complex with the hydrophobic ridge of the catalytic core. (c) The interface between the distal CTD hydrophobic patch and the N-terminal helix 
of $\mathrm{Ga}_{\mathrm{q}}$, burying $\sim 850 \AA^{2}$ of accessible surface area. (d) The interface between the Da3 helix and the hydrophobic ridge of the catalytic core, burying $\sim 1000 \AA^{2}$ of accessible surface area. 


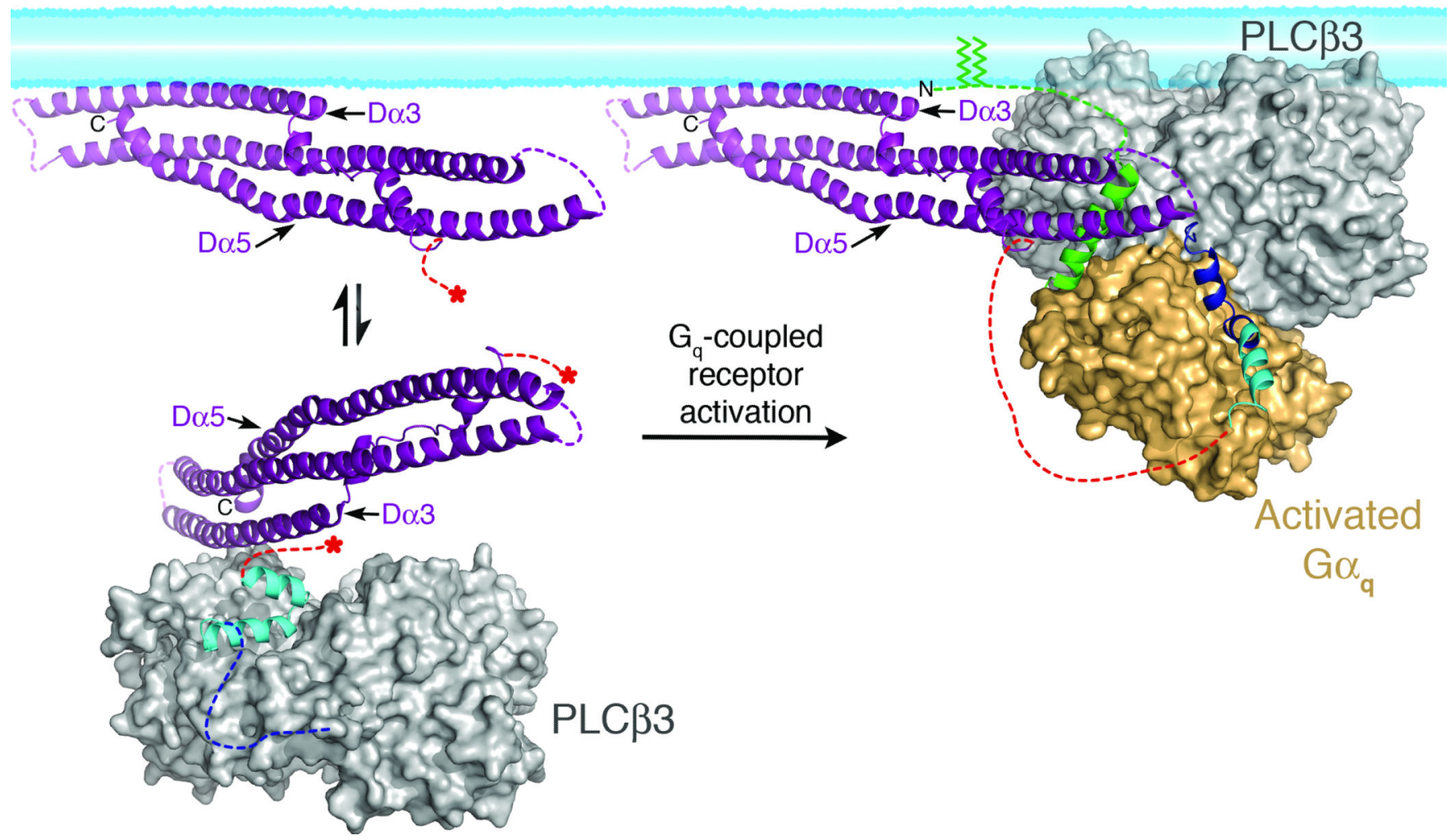

Figure 5.

Model of PLC $\beta 3$ regulation by the distal CTD and $\mathrm{Ga}_{\mathrm{q}}$. In the absence of $\mathrm{Ga}_{\mathrm{q}}$ (left), the Ha2' inhibitory helix from the proximal CTD (cyan), is bound to the catalytic core (gray surface), stabilizing the enzyme in a more quiescent conformation (based on PDB entry 3QR0) ${ }^{19}$. The primary $\mathrm{Ga}_{\mathrm{q}}$ binding site (dashed blue line) is disordered in this state. The distal (purple) and proximal CTDs are connected by the disordered CTD linker (dashed red lines). Red asterisks mark the start and end of the linker in the basal state. The distal CTD could help partition the enzyme between membrane-associated and cytosolic populations by forming a transient interaction with the hydrophobic ridge of the catalytic core (see Fig. 4b, d). Upon activation, $\mathrm{Ga}_{\mathrm{q}}$ binds to the Ha1-Ha2 helical hairpin (blue), displacing $\mathrm{Ha} 2$ ' from the catalytic core. The hydrophobic patch of the distal CTD engages the N-terminal helix of $\mathrm{Ga}_{\mathrm{q}}$ (green), and helps orient the catalytic core of PLC $\beta$ with respect to the lipid bilayer. The palmitoylated cysteines of the $\mathrm{Ga}_{\mathrm{q}} \mathrm{N}$-terminus (green lines) also help anchor the complex at the membrane. This model was created by independently docking the N-terminal helix of $\mathrm{Ga}_{\mathrm{q}}$ in complex with the distal CTD, and the remainder of $\mathrm{Ga}_{\mathrm{q}}$ in complex with the PLC $\beta 3$ core at a common membrane surface, then translating the distal CTD complex such that the $\mathrm{Ga}_{\mathrm{q}} \mathrm{N}$-terminal helix makes a reasonable connection to the rest of $\mathrm{Ga}_{\mathrm{q}}$. The model also brings the $\mathrm{PH}$ domain in close proximity to the membrane, consistent with studies indicating this domain also contributes to membrane binding ${ }^{44,47}$. 


\section{Table 1}

\section{Data collection and refinement statistics}

\begin{tabular}{|c|c|}
\hline & $\mathrm{Ga}_{\mathrm{q}}-\mathbf{P L C} \beta 3$ \\
\hline \multicolumn{2}{|l|}{ Data collection } \\
\hline Space group & $P 2_{1} 2_{1} 2_{1}$ \\
\hline \multicolumn{2}{|l|}{ Cell dimensions } \\
\hline$a, b, c(\AA)$ & $91.2,190,291$ \\
\hline$a, \beta, \gamma\left(^{\circ}\right)$ & $90,90,90$ \\
\hline Resolution (§̊) & $20.0-4.00(4.07-4.00)^{*}$ \\
\hline$R_{\text {merge }}$ & $0.14(0.33)$ \\
\hline$I / \sigma I$ & $8.8(1.9)$ \\
\hline Completeness (\%) & $76.7(36.7)$ \\
\hline Redundancy & $3.3(2.1)$ \\
\hline \multicolumn{2}{|l|}{ Refinement } \\
\hline Resolution ( & $20.0-4.0$ \\
\hline No. reflections & 32,433 \\
\hline$R_{\text {work }} / R_{\text {free }}$ & $0.214 / 0.255$ \\
\hline \multicolumn{2}{|l|}{ No. atoms } \\
\hline Protein & 39,306 \\
\hline Ligand/ion & 98 \\
\hline \multicolumn{2}{|l|}{$B$-factors $\left(\AA^{2}\right)$} \\
\hline Protein & 136 \\
\hline Ligand/ion & 100 \\
\hline \multicolumn{2}{|l|}{ R.m.s. deviations } \\
\hline Bond lengths $(\AA)$ & 0.005 \\
\hline Bond angles $\left({ }^{\circ}\right)$ & 0.86 \\
\hline
\end{tabular}

Values in parentheses are for highest-resolution shell. Data sets collected from multiple regions of two crystals were merged, and a $\sigma$ cutoff of 0 was applied during scaling to help limit the effects of radiation damage that occurred over each sweep of data. The data was $85.6 \%$ complete at 6.8 Å resolution. Before applying the $\sigma$ cutoff, there were 41,201 total reflections, corresponding to $91.1 \%$ overall completeness. 
ב্

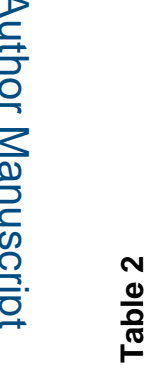

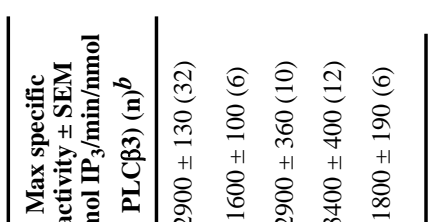

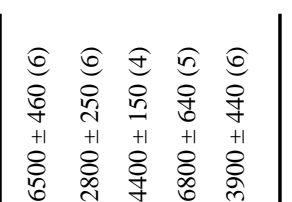

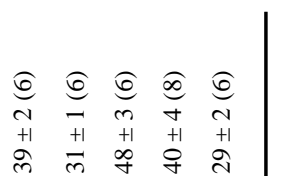

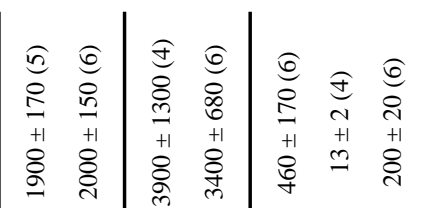

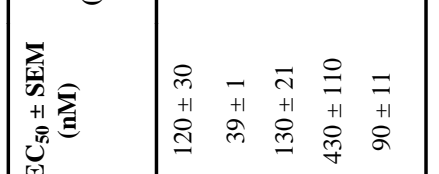

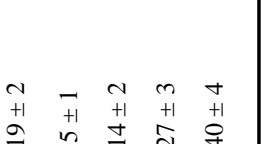

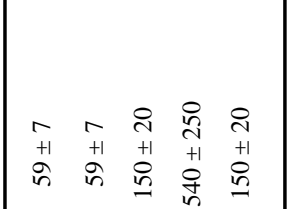

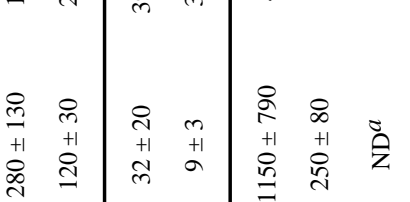

를

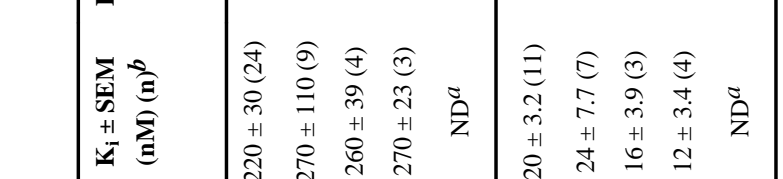

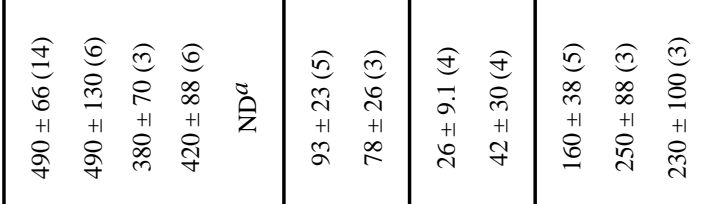

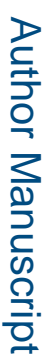

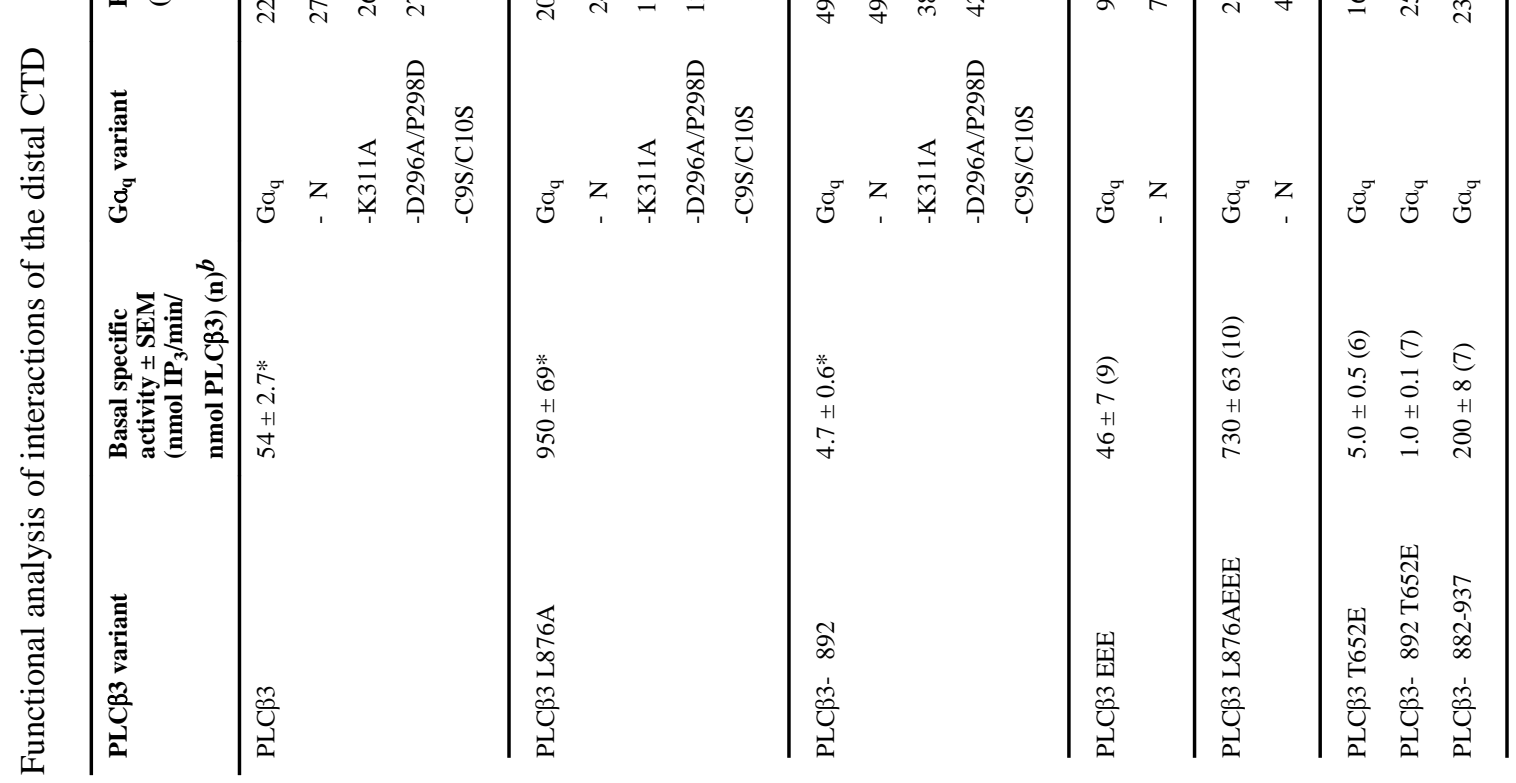

Nat Struct Mol Biol. Author manuscript; available in PMC 2013 September 01. 


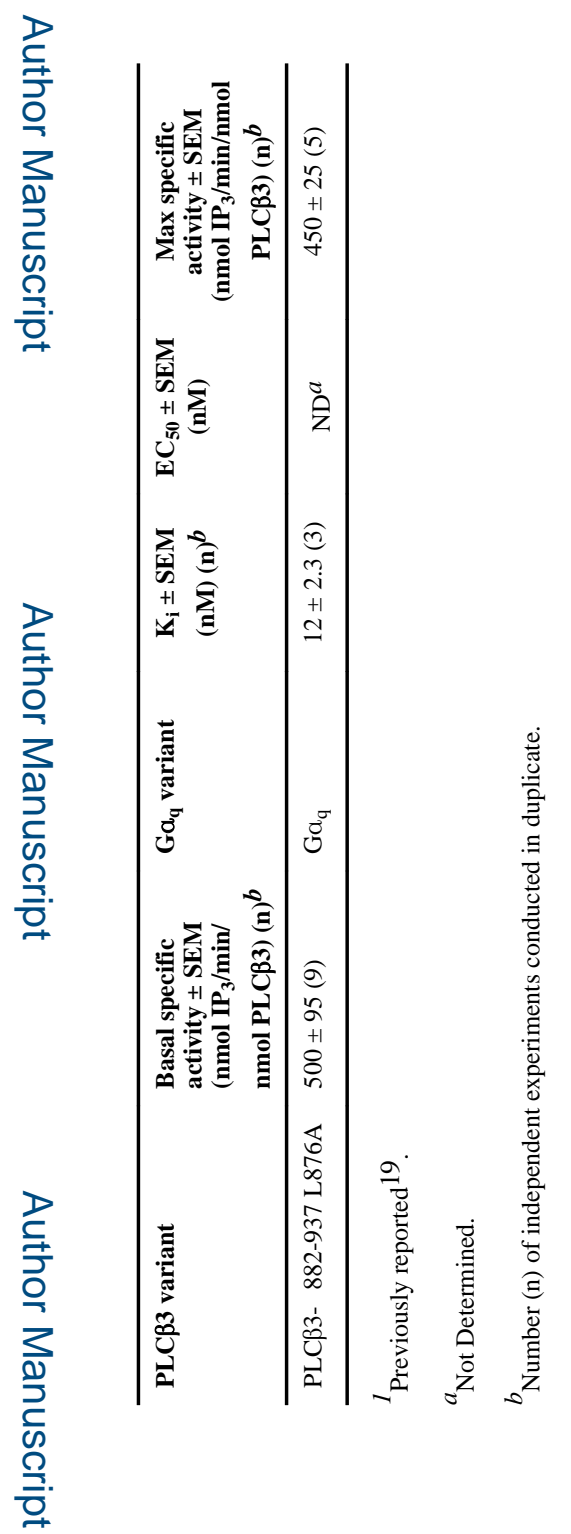

